\title{
El envejecimiento demográfico del Mediterráneo: 1950-2050
}

\section{The aging of the Mediterranean: 1950-2050}

\author{
Francisco Zamora López*, \\ Noelia Cámara Izquierdo**, 1 \\ “...la actual evolución demográfica representa un desafío de primer orden al \\ que hay que hacer frente con políticas adecuadas para acelerar el despegue eco- \\ nómico."
}

Declaración de Barcelona, 27-28 de noviembre de 1995

\section{INTRODUCCIÓN}

La última revisión de Naciones Unidas del año 2009 relativa a la evolución futura de la población mundial, prevé que en el curso del período 2000-2050, la población de 65 años o más aumente en cerca de 1100 millones de personas, alcanzando la cifra de 1487 millones en el año 2050, lo que representa un 16,2\% de la población del planeta, cuando éste contaba con tan sólo, si se puede decir esto, 131 millones de personas mayores en 1950 y 417 en 2000 , es decir, un 5,2 y un 6,8\%, respectivamente, de la población total.

Por su parte, EUROSTAT (2008), el organismo estadístico oficial de la Comunidad Europea, pronostica que en el año 2060, un 32,3\% de la población

\footnotetext{
* Universidad Complutense de Madrid (zamora@cps.ucm.es).

** Consejo Superior de Investigaciones Científicas (noelia@cti.csic.es).

${ }^{1}$ Los autores quieren agradecer a Alain Parant, investigador del Institut National d'Études Démographiques de Paris sus comentarios y apoyo a este artículo, así como a Micael Frenck por la actualización de los datos que ha realizado.
} 
española tendrá 65 o más años, es decir, 15 puntos más que en el año 2001 en el que alcanzaba un $17 \%$, mientras que la población total pasaría de 43 a cerca de 52 millones de habitantes².

A la vista de lo anterior, no cabe duda de que tanto en términos relativos (los de España), como en términos absolutos (los del conjunto del planeta), el incremento futuro de la población de 65 o más años, además de inexorable, va a representar uno de los retos de mayor envergadura a los que tendrán que enfrentarse los distintos gobiernos del mundo, incluyendo España. Para situar el proceso de envejecimiento en España desde una perspectiva internacional, se ha elegido centrarse en una región que sintetiza la diversidad de las poblaciones sometidas al envejecimiento, los países mediterráneos, y ello por distintas razones.

La importancia del Mediterráneo como reflejo de las contradicciones del planeta no presenta duda alguna. Las marcadas diferencias relativas a los niveles de desarrollo económico así como de diversos indicadores demográficos, tanto de fecundidad como de mortalidad e incluso de migraciones, la coexistencia de las tres grandes religiones monoteístas, de culturas ancestrales que han marcado y continúan marcando la historia de nuestro planeta, de imperios sucesivamente invasores e invadidos, etc., todos estos elementos configuran un conjunto único, una cuenca a la que se asoman y beben tres continentes: Europa, África y Asia. Aunque esta región se perciba como una zona de fricción de placas tectónicas o de civilizaciones o también como un lugar privilegiado de encuentros y de intercambios, el Mediterráneo es bastante más que el "mar en medio de las tierras" que le da nombre, el Medi Terraneum. Es un universo reducido que estará sometido a los avatares no sólo del cambio climático, sino también de aquellos de otra naturaleza que no tardarán en producirse. Desde este punto de vista, el envejecimiento de la población del Mediterráneo puede considerarse como uno de los principales desafíos sociales, económicos y políticos al que estará confrontado el conjunto de los países ribereños de esta zona del planeta, a más o menos largo plazo, más o menos rápidamente, de manera más o menos consciente y de forma más o menos dramática.

La Declaración de Barcelona del año 1995, intentó implantar las condiciones necesarias para el establecimiento de un espacio euro mediterráneo de libre-cambio en 2010. A un año de esta fecha, las condiciones no parecen estar reunidas de cara a alcanzar esta meta, aunque se hayan dado pasos en esta dirección. No obstante, debe subrayarse que uno de los objetivos de esta cons-

\footnotetext{
${ }^{2}$ Cabe resaltar que la población española alcanza actualmente cerca de 47 millones de habitantes según un avance del Padrón municipal a 1 de enero de 2009 publicado por el INE el 3 de junio de 2009.
} 
trucción, las migraciones humanas, constituyen una de las principales preocupaciones de los gobiernos, ya sea de la ribera noroeste del Mediterráneo que representa una de las principales zonas de llegada de migrantes, como de la ribera sureste que es su zona de salida. Sin embargo y más allá de esta preocupación relativa a un fenómeno demográfico, otros aspectos relativos a la demografía han sido olvidados o ignorados, en el marco de una política más integral de desarrollo y cooperación entre los distintos actores de la cuenca mediterránea. Se piensa, muy especialmente, en el envejecimiento progresivo del conjunto de las poblaciones mediterráneas que pocos estudios tienen en cuenta o incluso parecen todavía ignorar su existencia, si bien una parte de ellas, el "Norte", ya es objeto de preocupación por parte de sus dirigentes.

TABLA 1

EVOLUCIÓN Y CRECIMIENTO DE LA POBLACIÓN MUNDIAL Y DEL MEDITERRÁNEO SEGÚN GRANDES GRUPOS DE EDAD, 1950-2050 (EN MILES)

\begin{tabular}{cccccccc}
\hline & \multicolumn{3}{c}{ Población } & \multicolumn{3}{c}{ Crecimiento } \\
\hline Planeta & Año & 1950 & 2000 & 2050 & $1950-2050$ & $1950-2000$ & $2000-2050$ \\
\cline { 2 - 8 } & $0-19$ & 1.102 .307 & 2.421 .600 & 2.399 .586 & 1.297 .279 & 1.319 .293 & -22.014 \\
& $20-64$ & 1.296 .495 & 3.276 .525 & 5.263 .536 & 3.967 .041 & 1.980 .030 & 1.987 .011 \\
& 65 o más & 130.543 & 417.242 & 1.486 .861 & 1.356 .318 & 286.699 & 1.069 .619 \\
& Total & 2.529 .345 & 6.115 .367 & 9.149 .983 & 6.620 .638 & 3.586 .022 & 3.034 .616 \\
\cline { 2 - 8 } & (\%) & 1950 & 2000 & 2050 & $1950-2050$ & $1950-2000$ & $2000-2050$ \\
\cline { 2 - 8 } & 0-19 & 43,6 & 39,6 & 26,2 & 100,0 & 101,7 & $-1,7$ \\
& 20-64 & 51,3 & 53,6 & 57,5 & 100,0 & 49,9 & 50,1 \\
& 65 o más & 5,2 & 6,8 & 16,2 & 100,0 & 21,1 & 78,9 \\
Total & 100,0 & 100,0 & 100,0 & 100,0 & 54,2 & 45,8 \\
\hline Mediterráneo 0 & Año & 1950 & 2000 & 2050 & $1950-2050$ & $1950-2000$ & $2000-2050$ \\
\cline { 2 - 8 } & 0-19 & 85.673 & 153.036 & 145.543 & 59.870 & 67.363 & -7.493 \\
& 20-64 & 112.539 & 236.123 & 342.207 & 229.668 & 123.584 & 106.084 \\
& 65 o más & 14.815 & 43.138 & 126.565 & 111.750 & 28.323 & 83.427 \\
& Total & 213.027 & 432.297 & 614.315 & 401.288 & 219.270 & 182.018 \\
\cline { 2 - 8 } & (\%) & 1950 & 2000 & 2050 & $1950-2050$ & $1950-2000$ & $2000-2050$ \\
\cline { 2 - 8 } & 0-19 & 40,2 & 35,4 & 23,7 & 100,0 & 112,5 & $-12,5$ \\
20-64 & 52,8 & 54,6 & 55,7 & 100,0 & 53,8 & 46,2 \\
65 o más & 7,0 & 10,0 & 20,6 & 100,0 & 25,3 & 74,7 \\
Total & 100,0 & 100,0 & 100,0 & 100,0 & 54,6 & 45,4 \\
\hline
\end{tabular}

Fuente: United Nations, World Population Prospects, The 2008 Revision, www.un.org 
Si en 1950 (tabla 1), los 22 países ribereños del Mediterráneo ${ }^{3}$ contaban menos de 15 millones de personas de 65 o más años (UN, 2009), en el curso de los 50 años siguientes esta cifra fue multiplicada por cerca de 3 y alcanzó los 43 millones en 2000. Sin embargo, de aquí al año 2050, esta población debería prácticamente triplicarse de nuevo, lo que supondría más de 126 millones de personas mayores a esta fecha y representaría más del $20 \%$ del conjunto de la población mediterránea (gráfico 1). Más allá de estos datos, debe considerarse lo adelantado anteriormente, esto es que en el curso del mismo período 2000-2050, la población de 65 años o más debería incrementarse en cerca de 1100 millones de individuos en el conjunto del planeta, es decir, que éste contará con cerca de 1500 millones de "seniors" en 2050.

\section{GRÁFICO 1}

EVOLUCIÓN DE LA POBLACIÓN MEDITERRÁNEA SEGÚN GRANDES GRUPOS DE EDAD, 1950-2050

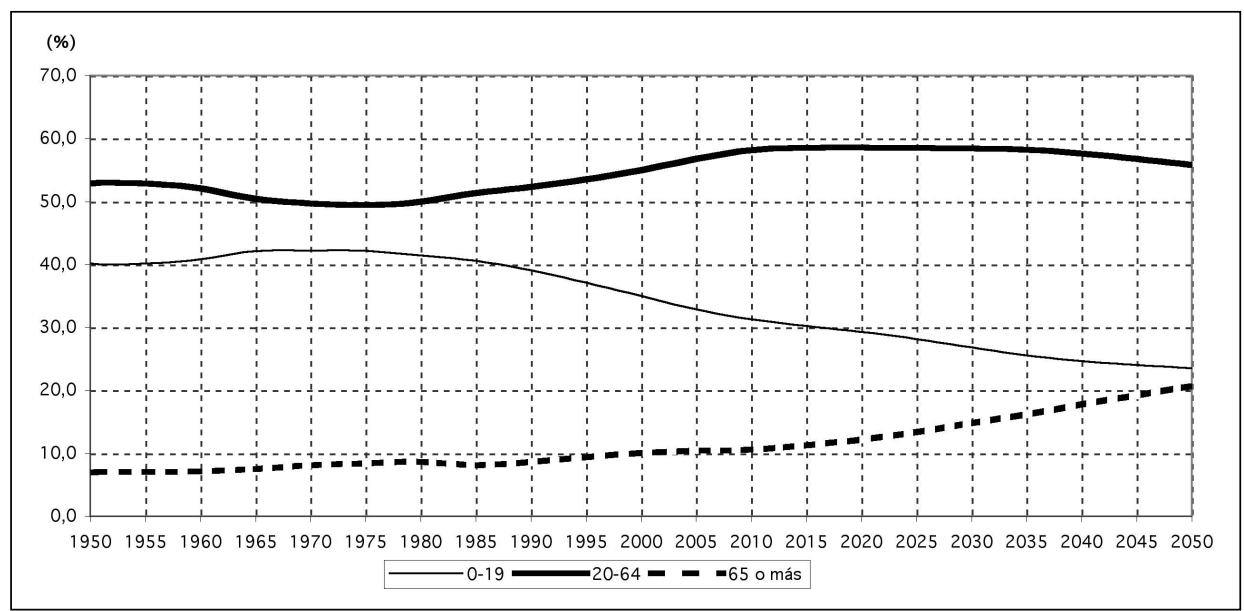

Fuente: United Nations, World Population Prospects, The 2008 Revision, www.un.org

En este artículo, se intenta analizar la evolución del envejecimiento demográfico en el seno de la población mediterránea en el curso del período 19502050. Se trata pues, de proporcionar una visión retrospectiva en un primer

${ }^{3}$ Los 22 países que han sido considerados son los siguientes: Albania, Argelia, Bosnia, Chipre, Croacia, Egipto, Eslovenia, España, Francia Grecia, Israel, Italia, Líbano, Libia, Malta, Marruecos, Mónaco, Serbia, Siria, Territorios Palestinos, Túnez y Turquía. Sin embargo, los datos relativos à Mónaco no han sido incluidos en el conjunto "Mediterráneo" en razón de la ausencia de datos equivalentes a los de los demás 21 estados que han sido utilizados. 
tiempo y prospectiva después, con la intención de poner en evidencia las diferencias que han existido y que permanecen todavía entre las distintas poblaciones, pero también de mostrar cómo se extiende el progresivo proceso de envejecimiento al conjunto de las poblaciones, a la vez que se mantienen entre ellas diferencias de todo tipo. Efectivamente, el Mediterráneo presenta una gran diversidad, no sólo en cuanto al calendario y al ritmo del fenómeno del envejecimiento -algunos países empezaron antes, otros más tarde, unos fueron más rápidos y otros menos- pero también en cuanto a su intensidad se refiere: algunos son más envejecidos y otros menos. Por otro lado, el Mediterráneo reúne, aproximadamente, en un espacio reducido, la diversidad que se observa en el conjunto del planeta, tanto desde el punto de vista de la progresión del envejecimiento demográfico, como desde el punto de vista de los factores que influyen en él.

\section{CAMBIOS DEMOGRÁFICOS}

En 1950, cerca de un habitante de cada doce del planeta, es decir, cerca de 213 millones de personas, vivía alrededor del Mediterráneo (tabla 2). En cincuenta años, esta población se ha duplicado y en el curso de los cincuenta próximos años, o sea en 2050, acabará por alcanzar, según los cálculos de

TABLA 2

EVOLUCIÓN DE LOS PESOS DE LA POBLACIÓN DEL MEDITERRÁNEO EN EL CONJUNTO MUNDIAL SEGÚN GRANDES GRUPOS DE EDAD, 1950-2050

\begin{tabular}{lccrc}
\hline Peso (en \%) & Año & 1950 & 2000 & 2050 \\
\cline { 2 - 5 } & $0-19$ & 7,77 & 6,32 & 6,07 \\
& $20-64$ & 8,68 & 7,21 & 6,50 \\
& 65 o más & 11,35 & 10,34 & 8,51 \\
& Total & 8,42 & 7,07 & 6,71 \\
\hline Evolución del peso (en \%) & Período & $1950-2050$ & $1950-2000$ & $2000-2050$ \\
\cline { 2 - 5 } & $0-19$ & $-1,71$ & $-1,45$ & $-0,25$ \\
& $20-64$ & $-2,18$ & $-1,47$ & $-0,71$ \\
& 65 o más & $-2,84$ & $-1,01$ & $-1,83$ \\
& Total & $-1,71$ & $-1,35$ & $-0,36$ \\
\hline
\end{tabular}

Fuente: United Nations, World Population Prospects, The 2008 Revision, www.un.org 
Naciones Unidas (2009) más de 614 millones de individuos, es decir, cerca de un habitante de cada quince de la población mundial o un $6,7 \%$ del total. La casi triplicación de la población mediterránea en el curso de estos 100 años, se ha traducido, en realidad, por una pérdida de su peso en el marco mundial, mostrando, de esta forma, una reducción de su ritmo de crecimiento y ello a pesar de una dinámica todavía intensa. Esta evolución, en apariencia contradictoria, no lo es tanto si se considera la composición bastante heteróclita de las poblaciones que constituyen el Mediterráneo.

A mediados del siglo pasado, las poblaciones de los distintos países que componen el Mediterráneo, presentaban enormes diferencias entre ellas y desde numerosos puntos de vista: mortalidad, fecundidad, migraciones, ritmos de crecimiento, tamaño, estructura, etc. De los cerca de 20 mil habitantes de Mónaco a los más de 46 millones de Italia, de los 7,38 hijos por mujer de los Territorios Palestinos a los 2,29 de Grecia, de los 42,7 años de esperanza de vida al nacimiento de Libia a los 67,1 años de Francia, todos los indicadores muestran distancias enormes cuando todas estas poblaciones son, de alguna manera, vecinas. De hecho, desde 1950, pero muy probablemente antes, se pueden distinguir tres Mediterráneos: un "Norte", un "Sur" y un "Oriente" 4 . Sea cual sea el indicador elegido, los distintos países se sitúan, de forma muy marcada, de una parte y otra de una media que sólo refleja una población "ficticia" y dibujan unos bloques de características claramente alejadas y que nada parece poder reunir, si no es su situación geográfica. En el año 2000, las diferencias permanecen y deberían, según toda probabilidad, seguir en 2050, incluso si Naciones Unidas propone, en el marco de sus hipótesis de evoluciones futuras, un amplio proceso de convergencia del conjunto de los comportamientos demográficos, del que se puede legítimamente dudar.

La observación de la edad mediana, permite sintetizar convenientemente lo que se ha resaltado anteriormente (tabla 3). De tal modo, en 1950-1955, se observa, por un lado, un grupo de poblaciones (Argelia, Bosnia, Libia, Marruecos, Siria, Territorios Palestinos y Turquía) cuya edad mediana es de 20 o menos años, es decir, una edad inferior a la observada a nivel mundial $(24,0$ años) y, por otro lado, un grupo de países por encima de este mismo nivel (Croacia, España, Eslovenia, Francia, Grecia, Israel, Italia y Serbia). Un grupo reducido de países se sitúa entre los dos precedentes (Albania, Chipre, Egipto,

\footnotetext{
${ }^{4}$ El Mediterráneo ha sido subdividido en tres subconjuntos: "Norte": Albania, Bosnia, Croacia, Eslovenia, España, Francia, Grecia, Italia, Malta, Serbia. "Sur": Argelia, Egipto, Libia, Marruecos, Túnez. "Oriente": Chipre, Israel, Líbano, Siria, T. Palestinos, Turquía.
} 
TABLA 3

EVOLUCIÓN DE LA EDAD MEDIANA DE LA POBLACIÓN MUNDIAL Y DE LOS PAÍSES DEL MEDITERRÁNEO, 1950-2050.

\begin{tabular}{|c|c|c|c|c|c|c|}
\hline Edad mediana & 1950 & 2000 & 2050 & $1950-2050$ & $1950-2000$ & $2000-2050$ \\
\hline Planeta & 24,0 & 26,6 & 38,4 & 14,4 & 2,6 & 11,8 \\
\hline Mediterráneo & 23,3 & 29,7 & 43,3 & 20,0 & 6,4 & 13,6 \\
\hline Med. Norte & 26,3 & 36,5 & 48,2 & 21,9 & 10,3 & 11,7 \\
\hline Albania & 20,6 & 26,9 & 44,3 & 23,7 & 6,3 & 17,4 \\
\hline Bosnia & 20,0 & 35,1 & 52,2 & 32,2 & 15,1 & 17,1 \\
\hline Croacia & 27,9 & 39,1 & 48,2 & 20,3 & 11,2 & 9,1 \\
\hline Eslovenia & 27,7 & 38,0 & 48,7 & 21,0 & 10,3 & 10,7 \\
\hline España & 27,7 & 37,6 & 48,2 & 20,5 & 9,9 & 10,6 \\
\hline Francia & 34,5 & 37,7 & 44,8 & 10,3 & 3,2 & 7,1 \\
\hline Grecia & 26,0 & 38,2 & 49,5 & 23,5 & 12,2 & 11,3 \\
\hline Italia & 28,6 & 40,3 & 50,5 & 21,9 & 11,7 & 10,2 \\
\hline Malta & 23,7 & 36,4 & 50,5 & 26,8 & 12,7 & 14,1 \\
\hline Serbia & 25,8 & 35,7 & 44,7 & 18,9 & 9,9 & 9,0 \\
\hline Med. Sur & 19,6 & 22,4 & 39,2 & 19,6 & 2,8 & 16,8 \\
\hline Argelia & 19,9 & 21,8 & 39,4 & 19,5 & 1,9 & 17,6 \\
\hline Egipto & 20,4 & 20,9 & 36,0 & 15,6 & 0,5 & 15,1 \\
\hline Libia & 19,0 & 22,1 & 39,1 & 20,1 & 3,1 & 17,0 \\
\hline Marruecos & 17,7 & 22,5 & 38,8 & 21,1 & 4,8 & 16,3 \\
\hline Túnez & 20,9 & 24,6 & 42,5 & 21,6 & 3,7 & 17,9 \\
\hline Med. Oriente & 21,4 & 24,5 & 38,5 & 17,1 & 3,1 & 14,1 \\
\hline Chipre & 23,7 & 33,5 & 44,4 & 20,7 & 9,8 & 10,9 \\
\hline Israel & 25,5 & 27,9 & 39,1 & 13,6 & 2,4 & 11,2 \\
\hline Líbano & 23,2 & 25,7 & 41,7 & 18,5 & 2,5 & 16,0 \\
\hline Siria & 19,4 & 18,7 & 36,4 & 17,0 & $-0,7$ & 17,7 \\
\hline T.Palestinos & 17,2 & 16,6 & 28,9 & 11,7 & $-0,6$ & 12,3 \\
\hline Turquía & 19,4 & 24,5 & 40,7 & 21,3 & 5,1 & 16,2 \\
\hline
\end{tabular}

Nota: Los datos relativos al conjunto del Mediterráneo, al "Norte", "Sur" y "Oriente", son las medias ponderadas del conjunto de los países que los componen.

Fuente: United Nations, World Population Prospects, The 2008 Revision, www.un.org

Líbano, Malta y Túnez), aunque más próximos de los primeros que de los segundos, más desarrollados en muchos aspectos. Cincuenta años más tarde, los diversos grupos mantienen, más o menos, su composición mientras que la edad mediana de la población mundial (26,6 años) sólo ha crecido en 2,6 
años. De tal forma, únicamente cuatro países han conseguido pasar de un nivel a otro: se trata de Bosnia cuyo aumento ha sido el más importante de todos los países mediterráneos, de Malta, de Chipre y de Albania. Sin embargo, frente a ganancias en ocasiones significativas, dos poblaciones han visto disminuir su edad mediana, se trata de Siria y de los Territorios Palestinos.

Excepto estos pocos cambios que traducen, en lo esencial, una difusión de los efectos del envejecimiento, las diferencias entre el país más joven y el menos se han incrementado: de 17,3 años en 1950, entre Francia y los Territorios Palestinos, se ha pasado a 23,7 años en 2000, entre Italia y los mismos Territorios Palestinos. Al horizonte del año 2050, las perspectivas de Naciones Unidas prevén un incremento sustancial de esta edad mediana que se incrementaría en más de 10 años para el conjunto del planeta (38,4 años). Las diferencias entre más y menos jóvenes deberían mantenerse en torno a los 23 años entre los Territorios Palestinos y Bosnia. Este aumento de la edad mediana refleja el proceso de envejecimiento de la población, aunque la simple consideración de este indicador, no permite concluir acerca del tipo de proceso en curso, es decir, en cuanto a poder determinar de forma evidente si se trata de un envejecimiento por la base o por la cúspide. No obstante, el análisis de la evolución de otros indicadores permite determinar cuánto, cuándo y cómo se ha producido el envejecimiento de las distintas poblaciones mediterráneas.

En 1950 (tabla 4 y mapa 1), la población mediterránea podía considerarse como una población joven: un 40,2\% de sus efectivos tenía menos de 20 años, mientras que un $7,0 \%$ tenía 65 o más años. Los Territorios Palestinos (55,5\%), Marruecos, Libia, Turquía, Siria o Argelia, seguidos de Albania, Bosnia, Egipto o Túnez con valores próximos al $50 \%$, son los países que cuentan con las proporciones más elevadas de población menor de 20 años, mientras que entre los países con menores proporciones se encuentran Eslovenia, España, Croacia, Italia o Francia con el menor peso, 30,2\%. En definitiva, se aprecian diferencias de más de 25 puntos entre los niveles extremos y una línea de división muy marcada entre el "Norte" y el "Oriente" o el "Sur" de la cuenca mediterránea $(34,8 \%, 50,5 \%$ y $50,6 \%$, respectivamente). En el otro extremo, o sea, entre las poblaciones que cuentan con las proporciones más elevadas de "seniors", se sitúan países como Francia (11,4\%), Italia, Croacia, Serbia o España, con niveles muy elevados si se comparan con los que presentan los Territorios Palestinos, Libia, Argelia, Siria, Bosnia, Israel, Turquía, Egipto o Marruecos, el país, este último, con menor proporción de personas mayores $(2,9 \%)$ de toda la ribera mediterránea. La misma división que se apreciaba precedentemente entre "Norte", "Oriente" y "Sur" se mantiene aquí $(8,7 \%$, $3,7 \%$ y $3,5 \%$, respectivamente) pero, curiosamente, el orden de los países más 
TABLA 4

POBLACIÓN MUNDIAL Y DE LOS PAÍSES DEL MEDITERRÁNEO SEGÚN GRANDES GRUPOS DE EDAD, 1950

\begin{tabular}{|c|c|c|c|c|c|c|c|c|c|}
\hline 1950 & $\begin{array}{c}\mathrm{P}_{0-19} / \mathrm{P}_{\text {tot }} \\
(\%)\end{array}$ & $\begin{array}{c}\mathrm{P}_{20-64} / \mathrm{P}_{\text {tot }} \\
(\%)\end{array}$ & $\begin{array}{c}\mathrm{P}_{65+} / \mathrm{P}_{\text {tot }} \\
(\%)\end{array}$ & $\begin{array}{c}\mathrm{P}_{65+} / \mathrm{P}_{0-19} \\
(\%)\end{array}$ & $\begin{array}{c}\mathrm{P}_{65+} / \mathrm{P}_{20.64} \\
(\%)\end{array}$ & $\mathrm{P}_{20-64} / \mathrm{P}_{65+}$ & $\begin{array}{c}\left(\mathrm{P}_{0-19}+\mathrm{P}_{65+}\right) \\
/ \mathrm{P}_{20-64} \\
(\%)\end{array}$ & $\begin{array}{c}\mathrm{P}_{80+} / \mathrm{P}_{\text {tot }} \\
(\%)\end{array}$ & $\begin{array}{c}\mathrm{P}_{80+} / \mathrm{P}_{65+} \\
(\%)\end{array}$ \\
\hline Planeta & 43,6 & 51,3 & 5,2 & 11,8 & 10,1 & 9,9 & 95,1 & 0,6 & 11,1 \\
\hline Mediterráneo & 40,2 & 52,8 & 7,0 & 17,3 & 13,2 & 7,6 & 89,3 & 0,9 & 12,8 \\
\hline Albania & 49,0 & 44,0 & 7,0 & 14,3 & 15,9 & 6,3 & 127,2 & 0,9 & 12,9 \\
\hline Argelia & 50,1 & 45,5 & 4,4 & 8,7 & 9,6 & 10,4 & 119,8 & 0,4 & 8,1 \\
\hline Bosnia & 49,9 & 46,1 & 4,0 & 8,1 & 8,7 & 11,5 & 117,0 & 0,5 & 13,1 \\
\hline Chipre & 43,8 & 50,3 & 5,9 & 13,4 & 11,6 & 8,6 & 98,8 & 0,6 & 10,3 \\
\hline Croacia & 36,2 & 55,9 & 7,9 & 21,8 & 14,1 & 7,1 & 79,0 & 1,2 & 14,8 \\
\hline Egipto & 49,3 & 47,7 & 3,0 & 6,1 & 6,3 & 15,9 & 109,5 & 0,2 & 5,6 \\
\hline Eslovenia & 36,7 & 56,3 & 7,1 & 19,2 & 12,5 & 8,0 & 77,7 & 1,0 & 14,4 \\
\hline España & 36,5 & 56,2 & 7,3 & 20,0 & 13,0 & 7,7 & 77,8 & 1,0 & 14,3 \\
\hline Francia & 30,2 & 58,4 & 11,4 & 37,7 & 19,5 & 5,1 & 71,2 & 1,6 & 14,0 \\
\hline Grecia & 39,0 & 54,2 & 6,8 & 17,4 & 12,5 & 8,0 & 84,5 & 1,0 & 15,2 \\
\hline Israel & 40,3 & 55,8 & 3,9 & 9,6 & 7,0 & 14,3 & 79,3 & 0,3 & 8,2 \\
\hline Italia & 35,4 & 56,5 & 8,1 & 22,9 & 14,3 & 7,0 & 76,9 & 1,0 & 12,9 \\
\hline Líbano & 44,1 & 48,6 & 7,2 & 16,3 & 14,8 & 6,8 & 105,6 & 0,9 & 12,5 \\
\hline Libia & 51,9 & 43,4 & 4,7 & 9,0 & 10,7 & 9,3 & 130,2 & 0,4 & 8,3 \\
\hline Malta & 43,9 & 50,3 & 5,8 & 13,1 & 11,5 & 8,7 & 98,7 & 0,6 & 11,1 \\
\hline Marruecos & 54,8 & 42,4 & 2,9 & 5,2 & 6,8 & 14,8 & 136,0 & 0,2 & 6,2 \\
\hline Serbia & 38,4 & 54,0 & 7,6 & 19,9 & 14,1 & 7,1 & 85,2 & 1,2 & 15,4 \\
\hline Siria & 51,2 & 44,4 & 4,3 & 8,4 & 9,7 & 10,3 & 125,0 & 0,4 & 8,5 \\
\hline T.Palestinos & 55,5 & 39,8 & 4,8 & 8,6 & 12,0 & 8,3 & 151,5 & 0,4 & 8,3 \\
\hline Túnez & 48,4 & 45,9 & 5,7 & 11,9 & 12,5 & 8,0 & 117,9 & 0,9 & 15,8 \\
\hline Turquía & 51,3 & 45,5 & 3,2 & 6,2 & 7,0 & 14,2 & 119,9 & 0,3 & 8,2 \\
\hline Med. Norte & 34,8 & 56,4 & 8,7 & 25,0 & 15,4 & 6,5 & 77,2 & 1,2 & 13,8 \\
\hline Med. Sur & 50,6 & 45,9 & 3,5 & 6,9 & 7,6 & 13,1 & 117,7 & 0,3 & 7,7 \\
\hline Med. Oriente & 50,5 & 45,8 & 3,7 & 7,3 & 8,0 & 12,5 & 118,1 & 0,3 & 8,7 \\
\hline
\end{tabular}

Fuente: United Nations, World Population Prospects, The 2008 Revision, www.un.org

jóvenes no se mantiene exactamente, o sea, que no se produce una relación directa entre los más jóvenes y los menos mayores. Así lo muestra, por ejemplo, el caso de los Territorios Palestinos que presentan, por otro lado, otra peculiaridad: la de ser la población con la menor proporción de personas potencialmente activas (20-64 años) con menos del 40\% de su población to- 


\section{MAPA 1}

EVOLUCIÓN DE LA POBLACIÓN DE 65 O MÁS AÑOS ENTRE LA POBLACIÓN TOTAL DE LOS PAÍSES DEL MEDITERRÁNEO, 1950-2050

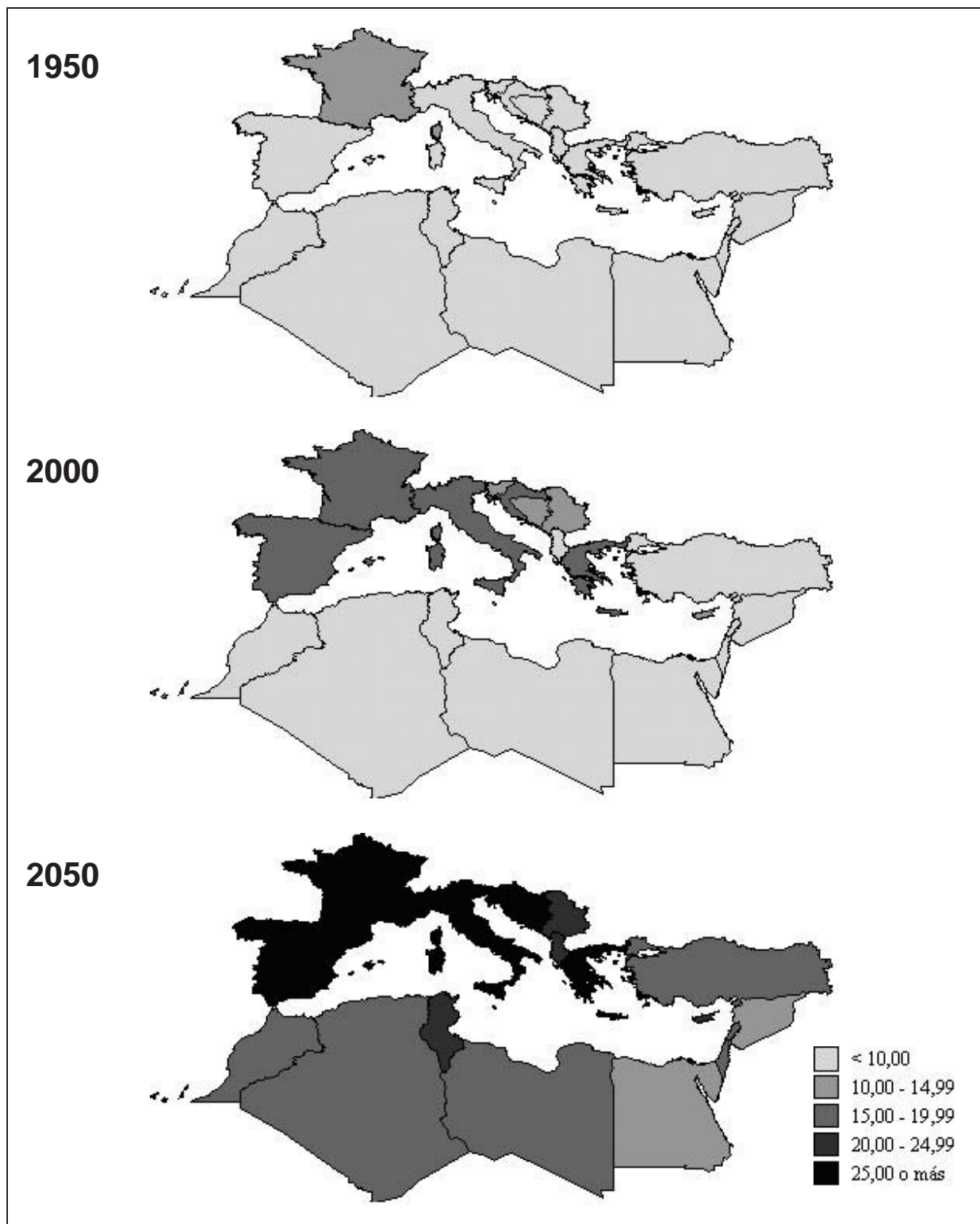

Fuente: United Nations, World Population Prospects, The 2008 Revision, www.un.org

Estudios Geográficos, Vol. LXX, 267, pp. 661-705, julio-diciembre 2009 ISSN: 0014-1496, eISSN: 1988-8546, doi: 10.3989/estgeogr.0469 
tal, cuando la media del conjunto del Mediterráneo es de, aproximadamente, un 53\%. Como consecuencia de ello, no sólo la relación entre mayores y potencialmente activos, $\mathrm{P}_{65+} / \mathrm{P}_{20-64}$, es relativamente baja en la cuenca mediterránea, $13,2 \%$, aunque superior a la del planeta, $10,1 \%$, sino que la ratio inactivos/potencialmente activos, $\left(\mathrm{P}_{0-19}+\mathrm{P}_{65+}\right) / \mathrm{P}_{20-64}$, se mantiene en un nivel relativamente bajo, $89,3 \%$, con respecto a la del conjunto del mundo, $95,1 \%$, si se tiene en cuenta la menor presencia de jóvenes que compensa, en cierta manera, una proporción ligeramente más elevada de mayores. De hecho, en estos primero tiempos del envejecimiento demográfico, la relación entre población potencialmente activa e inactiva es más favorable a los países más desarrollados que a los que lo son menos como lo muestra, una vez más, la diferencia entre el "Norte", 77,2\% y el "Oriente", 118,1\%, o el "Sur", 117,7\%.

Por último, debe resaltarse lo que en ese momento sólo era el principio de un fenómeno que va a ir tomando una relevancia cada vez más notable, tanto por los factores que permiten su desarrollo, como por sus implicaciones económicas y sociales: se trata de la presencia creciente de personas de 80 o más años (mapa 2), es decir, de una población de edad muy alta, con respecto al conjunto de aquellas que ya se denominan "seniors". En 1950, menos de un $1 \%$ de la población del Mediterráneo tiene 80 o más años, o sea, ligeramente más que la proporción observada para el conjunto del planeta. Sin embargo, las diferencias entre el "Norte" y el "Oriente" o el "Sur", parecen indicar, de nuevo, que el camino seguido en el curso de los cincuenta años siguientes va a estar ligado, no sólo a una reducción de la mortalidad sino, también, a unas diferencias socioeconómicas ya existentes y que, para algunas de ellas, van a mantenerse cuando no incrementarse.

En definitiva, el Mediterráneo de mediados del siglo xx se caracteriza por una muy fuerte polarización desde el punto de vista de su estructura por edad que no es sino el reflejo de diferencias de otra naturaleza: culturales, políticas, económicas, educativas, sanitarias, etc.

Cincuenta años más tarde, en el año 2000 (tabla 5), se aprecia cómo se ha reducido el peso de la población joven $(35,4 \%)$, mientras aumentaba el de las personas mayores $(10,0 \%)$. Si este proceso se observa en la mayoría de los países del Mediterráneo, algunas poblaciones presentan, sin embargo, evoluciones algo atípicas. De tal modo, por ejemplo, tanto en Siria como en los Territorios Palestinos, se aprecia un incremento del peso de la población joven en el conjunto de la población, así como una disminución de la de los "seniors", en contra de la evolución mayoritaria. No obstante, quizás resulte más interesante resaltar algunas transformaciones que ilustran las transiciones demográficas a las que han estado sometidas las estructuras por edad de algunos 


\section{MAPA 2}

EVOLUCIÓN DE LA POBLACIÓN DE 80 O MÁS AÑOS ENTRE LA POBLACIÓN TOTAL DE LOS PAÍSES DEL MEDITERRÁNEO, 1950-2050

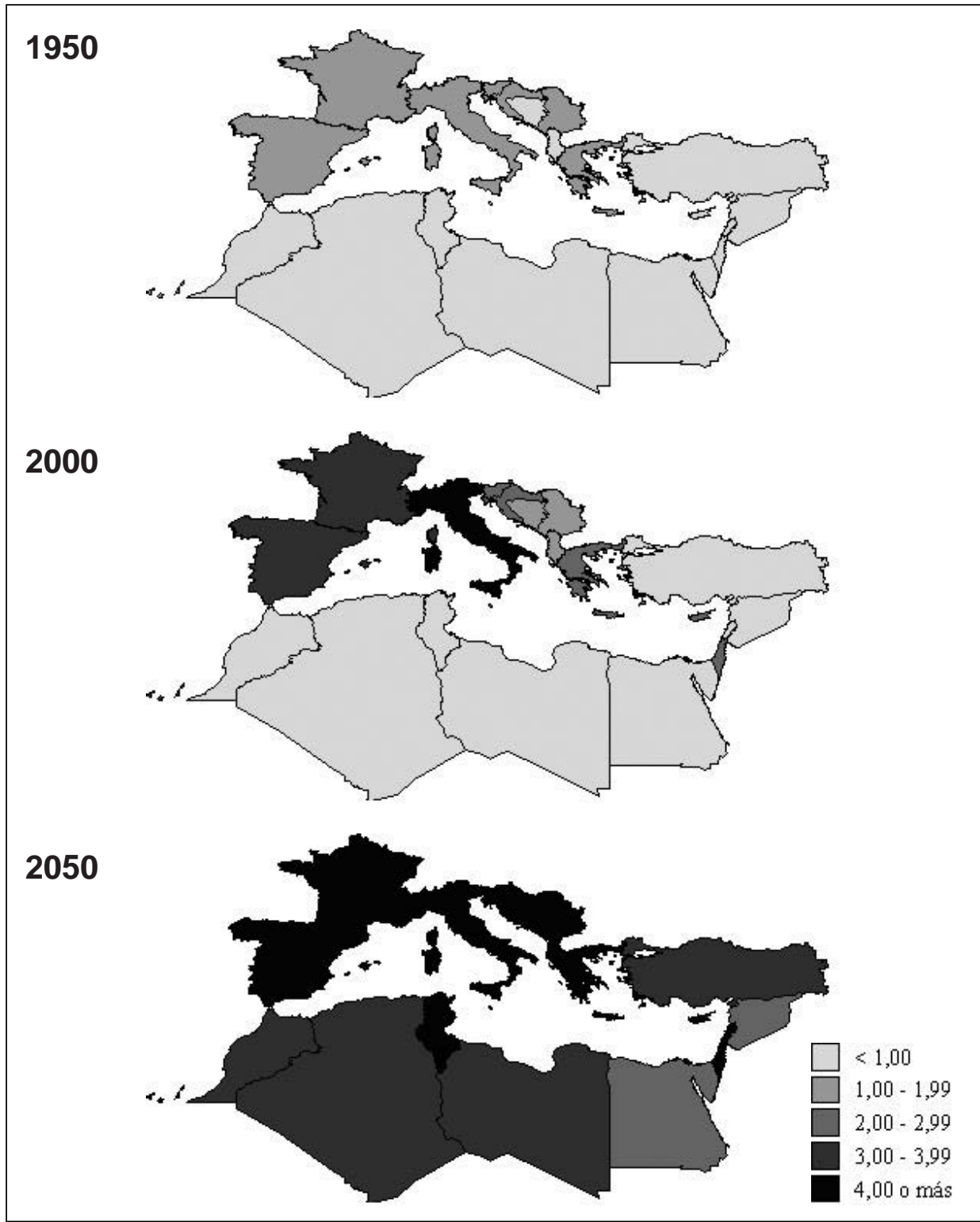

Fuente: United Nations, World Population Prospects, The 2008 Revision, www.un.org

Estudios Geográficos, Vol. LXX, 267, pp. 661-705, julio-diciembre 2009 ISSN: 0014-1496, eISSN: 1988-8546, doi: 10.3989/estgeogr.0469 
países, en un paso apresurado de lo que se podría denominar de lo "tradicional" hacia lo "moderno", o en un acercamiento incipiente entre el "Norte" y, el "Sur" y el "Oriente".

TABLA 5

POBLACIÓN MUNDIAL Y DE LOS PAÍSES DEL MEDITERRÁNEO SEGÚN GRANDES GRUPOS DE EDAD, 2000

\begin{tabular}{|c|c|c|c|c|c|c|c|c|c|}
\hline 2000 & $\begin{array}{c}\mathrm{P}_{0-19} / \mathrm{P}_{\text {tot }} \\
(\%)\end{array}$ & $\begin{array}{c}\mathrm{P}_{20-64} / \mathrm{P}_{\text {tot }} \\
(\%)\end{array}$ & $\begin{array}{c}\mathrm{P}_{65+} / \mathrm{P}_{\text {tot }} \\
(\%)\end{array}$ & $\begin{array}{c}\mathrm{P}_{65+} / \mathrm{P}_{0-19} \\
(\%)\end{array}$ & $\begin{array}{c}\mathrm{P}_{65+} / \mathrm{P}_{20-64} \\
(\%)\end{array}$ & ${ }_{4} \mathrm{P}_{20-64} / \mathrm{P}_{65+}$ & $\begin{array}{c}\left(\mathrm{P}_{0-19}+\mathrm{P}_{65+}\right) \\
/ \mathrm{P}_{20-64} \\
(\%)\end{array}$ & $\begin{array}{c}\mathrm{P}_{80+} / \mathrm{P}_{\text {tot }} \\
(\%)\end{array}$ & $\begin{array}{c}\mathrm{P}_{80+} / \mathrm{P}_{65+} \\
(\%)\end{array}$ \\
\hline Planeta & 39,6 & 53,6 & 6,8 & 17,2 & 12,7 & 7,9 & 86,6 & 1,1 & 16,8 \\
\hline Mediterráneo & 35,4 & 54,6 & 10,0 & 28,2 & 18,3 & 5,5 & 83,1 & 1,9 & 19,2 \\
\hline Albania & 39,9 & 52,7 & 7,4 & 18,5 & 14,0 & 7,1 & 89,7 & 1,1 & 14,5 \\
\hline Argelia & 46,3 & 49,5 & 4,2 & 9,1 & 8,5 & 11,8 & 101,9 & 0,6 & 13,8 \\
\hline Bosnia & 27,6 & 61,4 & 11,0 & 40,0 & 18,0 & 5,6 & 63,0 & 1,2 & 10,8 \\
\hline Chipre & 30,6 & 58,1 & 11,3 & 36,9 & 19,5 & 5,1 & 72,2 & 2,4 & 21,3 \\
\hline Croacia & 23,9 & 60,5 & 15,6 & 65,3 & 25,7 & 3,9 & 65,2 & 2,2 & 14,0 \\
\hline Egipto & 48,2 & 47,5 & 4,3 & 8,9 & 9,0 & 11,1 & 110,6 & 0,5 & 10,8 \\
\hline Eslovenia & 22,9 & 63,0 & 14,0 & 61,2 & 22,3 & 4,5 & 58,7 & 2,3 & 16,5 \\
\hline España & 21,3 & 61,9 & 16,8 & 79,0 & 27,2 & 3,7 & 61,6 & 3,8 & 22,6 \\
\hline Francia & 25,5 & 58,4 & 16,1 & 63,3 & 27,6 & 3,6 & 71,2 & 3,8 & 23,8 \\
\hline Grecia & 22,0 & 61,5 & 16,5 & 74,9 & 26,8 & 3,7 & 62,6 & 2,9 & 17,3 \\
\hline Israel & 36,9 & 53,1 & 9,9 & 26,8 & 18,6 & 5,4 & 88,2 & 2,1 & 21,2 \\
\hline Italia & 19,6 & 61,9 & 18,4 & 93,8 & 29,8 & 3,4 & 61,5 & 4,3 & 23,1 \\
\hline Líbano & 40,0 & 53,2 & 6,8 & 16,9 & 12,8 & 7,8 & 88,1 & 0,8 & 12,5 \\
\hline Libia & 45,2 & 51,4 & 3,3 & 7,4 & 6,5 & 15,4 & 94,4 & 0,4 & 12,3 \\
\hline Malta & 27,3 & 60,3 & 12,4 & 45,3 & 20,5 & 4,9 & 65,8 & 2,3 & 18,8 \\
\hline Marruecos & 45,1 & 50,2 & 4,7 & 10,4 & 9,3 & 10,7 & 99,3 & 0,6 & 12,3 \\
\hline Serbia & 27,6 & 58,8 & 13,6 & 49,5 & 23,2 & 4,3 & 70,0 & 1,6 & 11,9 \\
\hline Siria & 53,4 & 43,6 & 3,0 & 5,7 & 6,9 & 14,4 & 129,3 & 0,4 & 11,8 \\
\hline T.Palestinos & 56,8 & 39,7 & 3,5 & 6,1 & 8,7 & 11,5 & 151,7 & 0,5 & 15,6 \\
\hline Túnez & 40,9 & 52,8 & 6,3 & 15,4 & 11,9 & 8,4 & 89,3 & 0,8 & 13,3 \\
\hline Turquía & 41,0 & 53,8 & 5,3 & 12,8 & 9,8 & 10,2 & 86,0 & 0,5 & 9,5 \\
\hline Med. Norte & 23,0 & 60,5 & 16,6 & 72,1 & 27,4 & 3,6 & 65,4 & 3,6 & 21,9 \\
\hline Med. Sur & 46,6 & 49,0 & 4,4 & 9,5 & 9,1 & 11,0 & 104,3 & 0,5 & 12,0 \\
\hline Med. Oriente & 43,2 & 51,5 & 5,2 & 12,1 & 10,1 & 9,9 & 94,0 & 0,6 & 11,6 \\
\hline
\end{tabular}

Fuente: United Nations, World Population Prospects, the 2008 Revision, www.un.org 
En este caso de intensa disminución del peso de los jóvenes (tabla 6), se encuentra Bosnia (22 puntos menos, de 49,9\% a 27,6\%), Grecia (17 puntos menos), Malta (cerca de 17 puntos menos) o Eslovenia (14 puntos menos). Simultáneamente y como, por otro lado, era probable que se produjese, el

TABLA 6

EVOLUCIÓN DE LA POBLACIÓN MUNDIAL Y DE LOS PAÍSES DEL MEDITERRÁNEO SEGÚN GRANDES GRUPOS DE EDAD, 1950-2000

\begin{tabular}{|c|c|c|c|c|c|c|c|c|c|}
\hline $1950-2000$ & $\begin{array}{c}\mathrm{P}_{0-19} / \mathrm{P}_{\text {tot }} \\
(\%)\end{array}$ & $\begin{array}{c}\mathrm{P}_{20-64} / \mathrm{P}_{\text {tot }} \\
(\%)\end{array}$ & $\begin{array}{c}\mathrm{P}_{65+} / \mathrm{P}_{\mathrm{tot}} \\
(\%)\end{array}$ & $\begin{array}{c}\mathrm{P}_{65+} / \mathrm{P}_{0-19} \\
(\%)\end{array}$ & $\begin{array}{c}\mathrm{P}_{65+} / \mathrm{P}_{20-64} \\
(\%)\end{array}$ & $\mathrm{P}_{20-64} / \mathrm{P}_{65+}$ & $\begin{array}{c}\left(\mathrm{P}_{0-19}+\mathrm{P}_{65+}\right) \\
/ \mathrm{P}_{20-64} \\
(\%)\end{array}$ & $\begin{array}{c}\mathrm{P}_{80+} / \mathrm{P}_{\text {tot }} \\
(\%)\end{array}$ & $\begin{array}{c}\mathrm{P}_{80+} / \mathrm{P}_{65+} \\
(\%)\end{array}$ \\
\hline Planeta & $-4,0$ & 2,3 & 1,7 & 5,4 & 2,7 & $-2,1$ & $-8,4$ & 0,6 & 5,7 \\
\hline Mediterráneo & $-4,8$ & 1,8 & 3,0 & 10,9 & 5,1 & $-2,1$ & $-6,2$ & 1,0 & 6,4 \\
\hline Albania & $-9,1$ & 8,7 & 0,4 & 4,2 & $-1,9$ & 0,8 & $-37,4$ & 0,2 & 1,6 \\
\hline Argelia & $-3,9$ & 4,0 & $-0,2$ & 0,3 & $-1,2$ & 1,4 & $-18,0$ & 0,2 & 5,7 \\
\hline Bosnia & $-22,3$ & 15,3 & 7,0 & 31,9 & 9,3 & $-5,9$ & $-54,0$ & 0,7 & $-2,3$ \\
\hline Chipre & $-13,2$ & 7,8 & 5,5 & 23,6 & 7,8 & $-3,5$ & $-26,6$ & 1,8 & 11,0 \\
\hline Croacia & $-12,4$ & 4,7 & 7,7 & 43,5 & 11,6 & $-3,2$ & $-13,8$ & 1,0 & $-0,8$ \\
\hline Egipto & $-1,0$ & $-0,2$ & 1,3 & 2,7 & 2,7 & $-4,8$ & 1,1 & 0,3 & 5,2 \\
\hline Eslovenia & $-13,7$ & 6,7 & 7,0 & 42,0 & 9,8 & $-3,5$ & $-19,0$ & 1,3 & 2,1 \\
\hline España & $-15,2$ & 5,7 & 9,5 & 59,0 & 14,2 & $-4,0$ & $-16,2$ & 2,8 & 8,3 \\
\hline Francia & $-4,7$ & 0,0 & 4,7 & 25,6 & 8,1 & $-1,5$ & 0,0 & 2,3 & 9,9 \\
\hline Grecia & $-17,0$ & 7,3 & 9,7 & 57,5 & 14,3 & $-4,2$ & $-22,0$ & 1,8 & 2,1 \\
\hline Israel & $-3,4$ & $-2,6$ & 6,0 & 17,2 & 11,7 & $-9,0$ & 8,8 & 1,8 & 13,1 \\
\hline Italia & $-15,7$ & 5,4 & 10,3 & 71,0 & 15,5 & $-3,6$ & $-15,4$ & 3,2 & 10,2 \\
\hline Líbano & $-4,1$ & 4,5 & $-0,4$ & 0,6 & $-2,1$ & 1,1 & $-17,5$ & $-0,1$ & 0,0 \\
\hline Libia & $-6,7$ & 8,0 & $-1,3$ & $-1,6$ & $-4,2$ & 6,1 & $-35,8$ & 0,0 & 4,0 \\
\hline Malta & $-16,6$ & 10,0 & 6,6 & 32,1 & 9,0 & $-3,8$ & $-32,9$ & 1,7 & 7,6 \\
\hline Marruecos & $-9,6$ & 7,8 & 1,8 & 5,1 & 2,6 & $-4,1$ & $-36,7$ & 0,4 & 6,1 \\
\hline Serbia & $-10,8$ & 4,8 & 6,0 & 29,6 & 9,1 & $-2,8$ & $-15,2$ & 0,4 & $-3,5$ \\
\hline Siria & 2,1 & $-0,8$ & $-1,3$ & $-2,8$ & $-2,8$ & 4,2 & 4,3 & 0,0 & 3,3 \\
\hline T.Palestinos & 1,3 & 0,0 & $-1,3$ & $-2,5$ & $-3,3$ & 3,1 & 0,2 & 0,1 & 7,3 \\
\hline Túnez & $-7,5$ & 6,9 & 0,5 & 3,5 & $-0,6$ & 0,4 & $-28,6$ & $-0,1$ & $-2,5$ \\
\hline Turquía & $-10,3$ & 8,3 & 2,1 & 6,6 & 2,7 & $-4,0$ & $-33,8$ & 0,2 & 1,4 \\
\hline Med. Norte & $-11,9$ & 4,0 & 7,9 & 47,1 & 12,0 & $-2,8$ & $-11,8$ & 2,4 & 8,1 \\
\hline Med. Sur & $-3,9$ & 3,0 & 0,9 & 2,6 & 1,4 & $-2,0$ & $-13,4$ & 0,3 & 4,2 \\
\hline Med. Oriente & $-7,3$ & 5,7 & 1,6 & 4,8 & 2,1 & $-2,6$ & $-24,1$ & 0,3 & 3,0 \\
\hline
\end{tabular}

Fuente: United Nations, World Population Prospects, the 2008 Revision, www.un.org 
peso de las personas mayores en estas poblaciones se ha incrementado de forma significativa, si bien no lo ha hecho en la misma medida que los puntos perdidos anteriormente, aunque sí en una mayor proporción. España (15 puntos menos, de $36,5 \%$ a $21,3 \%$ ) e Italia (16 puntos menos, de $35,4 \%$ a $19,6 \%$ ), presentan igualmente reducciones importantes de sus proporciones de jóvenes, aunque partiendo de niveles más bajos ${ }^{5}$ que los anteriores, lo cual ha tenido como consecuencia el propulsar estos dos países a los primeros rangos mundiales del envejecimiento, en el umbral del siglo xxi. Sin embargo y contrariamente a lo que habría podido parecer, entre 1950 y 2000 las distancias entre el "Norte" y el "Oriente" o el "Sur" se han incrementado en cuanto a jóvenes se refiere, mientras que se producía el mismo fenómeno para los mayores, pero en el sentido contrario. Por su parte, los efectivos muestran una disminución de cerca de 4,9 millones de jóvenes en el "Norte", frente a unos incrementos próximos a los 27 millones en el "Oriente" y a los 45 millones en el "Sur", cuando en el otro extremo de la pirámide, los "seniors" del "Norte" aumentan en más de 19 millones, o sea, cuatro veces más que en el "Sur" (4,9 millones) y cinco veces más que en "Oriente" (4,0 millones).

Simultáneamente a estas evoluciones, la parte de los activos potenciales se ha incrementado entre las dos fechas de un $52,8 \%$ a un $54,6 \%$, lo que ha permitido reducir o mejorar si se prefiere, la relación entre inactivos y activos desde un $89,3 \%$ hasta un $83,1 \%$, es decir, 6,2 puntos menos. Sin embargo, la ratio activo por "senior" ha disminuido desde unos 7,6 en 1950 hasta unos 5,5 activos por "senior" en 2000, como consecuencia de un incremento del número y de la proporción de "seniors", superior al de los activos. El problema de la financiación de las jubilaciones se intensifica, incluso si, ceteris paribus, en un primer tiempo, el coste creciente de los "seniors" pudiera estar amortiguado por el coste decreciente de los jóvenes.

Otro fenómeno en alza, la población de 80 o más años representa en 2000 cerca de un $2 \%$ de la población mediterránea, o sea, más de 8 millones de individuos. Paralelamente a este proceso se produce un envejecimiento del envejecimiento con un incremento del peso de los individuos de 80 o más años entre los "seniors" (mapa 3): de un 12,8\% en 1950, estos pasan a un 19,2\% en 2000. A un nivel geográfico más fino, las diferencias son igualmente importantes. De tal modo, cerca de 14 puntos separan en el año 2000 a Francia de Turquía, mientras que cerca de 10 puntos separan el "Norte", 21,9\% del "Sur"

\footnotetext{
${ }^{5}$ La transición demográfica de estos países fue más precoz que la de los precedentes y figuraban ya entre los países denominados "modernos".
} 


\section{MAPA 3}

EVOLUCIÓN DE LA POBLACIÓN DE 80 AÑOS O MÁS ENTRE LA POBLACIÓN DE 65 AÑOS O MÁS EN LOS PAÍSES DEL MEDITERRÁNEO, 1950-2050

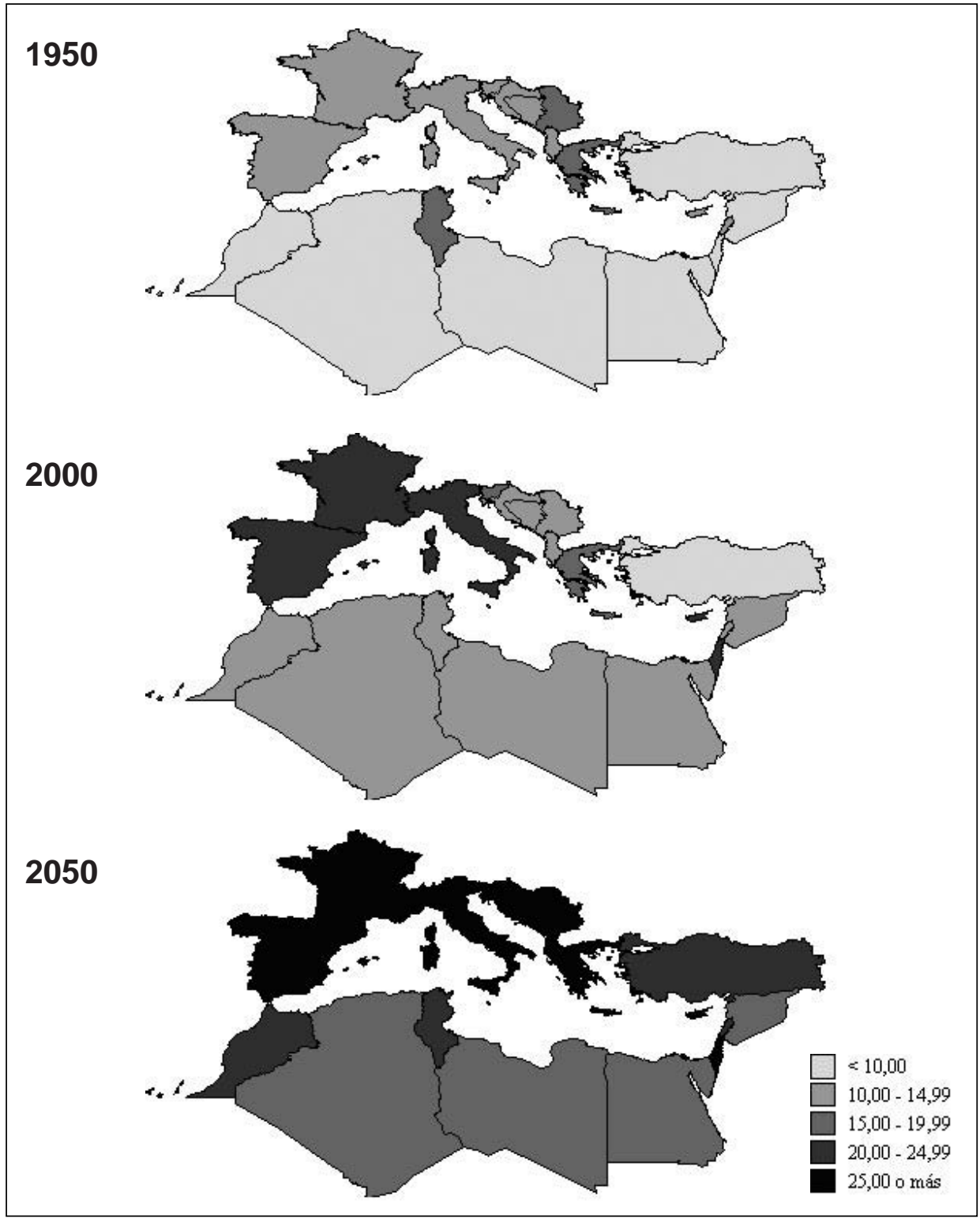

Fuente: United Nations, World Population Prospects, the 2008 Revision, www.un.org

Estudios Geográficos, Vol. LXX, 267, pp. 661-705, julio-diciembre 2009 ISSN: 0014-1496, eISSN: 1988-8546, doi: 10.3989/estgeogr.0469 
o de "Oriente", cerca de un 12,0\% cada uno, en lo que es un reflejo más de las diferencias que existen entre países desarrollados y países que lo son menos.

A mediados del nuevo siglo, en 2050 (tabla 7), no sólo se ha producido una intensificación del doble proceso de disminución de los jóvenes y de

TABLA 7

POBLACIÓN MUNDIAL Y DE LOS PAÍSES DEL MEDITERRÁNEO SEGÚN GRANDES GRUPOS DE EDAD, 2050

\begin{tabular}{|c|c|c|c|c|c|c|c|c|c|}
\hline 2050 & $\begin{array}{c}\mathrm{P}_{0-19} / \mathrm{P}_{\text {tot }} \\
(\%)\end{array}$ & $\begin{array}{c}\mathrm{P}_{20-64} / \mathrm{P}_{\text {tot }} \\
(\%)\end{array}$ & $\begin{array}{c}\mathrm{P}_{65+} / \mathrm{P}_{\mathrm{tot}} \\
(\%)\end{array}$ & $\begin{array}{c}\mathrm{P}_{65+} / \mathrm{P}_{0-19} \\
(\%)\end{array}$ & $\begin{array}{c}\mathrm{P}_{65+} / \mathrm{P}_{20-64} \\
(\%)\end{array}$ & $\mathrm{P}_{20-64} / \mathrm{P}_{65+}$ & $\begin{array}{c}\left(\mathrm{P}_{0-19}+\mathrm{P}_{65+}\right) \\
/ \mathrm{P}_{20-64} \\
(\%)\end{array}$ & $\begin{array}{c}\mathrm{P}_{80+} / \mathrm{P}_{\text {tot }} \\
(\%)\end{array}$ & $\begin{array}{c}\mathrm{P}_{80+} / \mathrm{P}_{65+} \\
(\%)\end{array}$ \\
\hline Planeta & 26,2 & 57,5 & 16,2 & 62,0 & 28,2 & 3,5 & 73,8 & 4,3 & 26,5 \\
\hline Mediterráneo & 23,7 & 55,7 & 20,6 & 87,0 & 37,0 & 2,7 & 79,5 & 6,0 & 28,9 \\
\hline Albania & 21,6 & 57,0 & 21,5 & 99,6 & 37,7 & 2,7 & 75,5 & 6,7 & 31,2 \\
\hline Argelia & 24,1 & 58,3 & 17,6 & 73,3 & 30,2 & 3,3 & 71,5 & 3,4 & 19,1 \\
\hline Bosnia & 16,0 & 53,7 & 30,4 & 190,4 & 56,6 & 1,8 & 86,4 & 9,1 & 30,1 \\
\hline Chipre & 21,0 & 55,8 & 23,3 & 111,0 & 41,7 & 2,4 & 79,2 & 7,4 & 31,9 \\
\hline Croacia & 19,3 & 52,5 & 28,2 & 146,4 & 53,7 & 1,9 & 90,4 & 9,3 & 32,8 \\
\hline Egipto & 27,7 & 59,2 & 13,1 & 47,3 & 22,2 & 4,5 & 69,0 & 2,3 & 17,6 \\
\hline Eslovenia & 18,8 & 51,0 & 30,2 & 161,0 & 59,2 & 1,7 & 96,0 & 10,5 & 34,9 \\
\hline España & 19,5 & 48,7 & 31,8 & 163,3 & 65,2 & 1,5 & 105,2 & 11,3 & 35,7 \\
\hline Francia & 21,8 & 51,3 & 26,9 & 123,4 & 52,5 & 1,9 & 95,0 & 11,3 & 41,9 \\
\hline Grecia & 18,1 & 50,6 & 31,3 & 172,7 & 61,9 & 1,6 & 97,7 & 10,7 & 34,1 \\
\hline Israel & 25,2 & 55,6 & 19,2 & 75,9 & 34,4 & 2,9 & 79,8 & 6,2 & 32,1 \\
\hline Italia & 18,0 & 48,8 & 33,3 & 184,9 & 68,2 & 1,5 & 105,1 & 13,4 & 40,4 \\
\hline Líbano & 22,9 & 57,8 & 19,3 & 84,2 & 33,3 & 3,0 & 72,9 & 4,3 & 22,3 \\
\hline Libia & 24,8 & 57,6 & 17,6 & 71,0 & 30,5 & 3,3 & 73,5 & 3,4 & 19,6 \\
\hline Malta & 16,9 & 53,7 & 29,4 & 174,3 & 54,7 & 1,8 & 86,1 & 9,4 & 32,0 \\
\hline Marruecos & 24,9 & 58,5 & 16,6 & 66,5 & 28,3 & 3,5 & 70,8 & 3,3 & 20,0 \\
\hline Serbia & 21,3 & 55,0 & 23,7 & 111,5 & 43,1 & 2,3 & 81,8 & 6,3 & 26,4 \\
\hline Siria & 26,8 & 59,8 & 13,4 & 50,1 & 22,4 & 4,5 & 67,1 & 2,4 & 17,8 \\
\hline T.Palestinos & 35,3 & 57,4 & 7,3 & 20,8 & 12,8 & 7,8 & 74,2 & 1,4 & 19,0 \\
\hline Túnez & 22,1 & 57,1 & 20,8 & 94,0 & 36,4 & 2,7 & 75,2 & 4,6 & 22,1 \\
\hline Turquía & 23,6 & 58,0 & 18,4 & 78,0 & 31,7 & 3,2 & 72,4 & 3,7 & 20,3 \\
\hline Med. Norte & 19,8 & 50,2 & 30,0 & 151,3 & 59,6 & 1,7 & 99,0 & 11,5 & 38,3 \\
\hline Med. Sur & 26,1 & 58,7 & 15,2 & 58,4 & 25,9 & 3,9 & 70,3 & 2,9 & 18,8 \\
\hline Med. Oriente & 25,1 & 58,2 & 16,7 & 66,3 & 28,6 & 3,5 & 71,8 & 3,5 & 20,9 \\
\hline
\end{tabular}

Fuente: United Nations, World Population Prospects, the 2008 Revision, www.un.org 
incremento de los mayores, sino que, además, la mayor parte de los países del Mediterráneo experimenta este fenómeno de envejecimiento demográfico, aunque según ritmos e intensidades distintos. En Italia, una persona de cada tres tendrá 65 años o más en 2050, mientras que en otros países como Bosnia, Croacia, España, Eslovenia, Francia, Grecia o Malta, esta proporción se acercará al 30\%. Todavía más significativo puede parecer el hecho de que determinados países que parecían inmunes a tales cambios demográficos, envejezcan a gran velocidad: Albania, Argelia, Líbano, Libia, Marruecos, Túnez o Turquía sobrepasarán el 15\%, mientras que únicamente Egipto, Siria y los Territorios Palestinos deberían registrar niveles inferiores a este mismo $15 \%$, estos últimos siendo, de lejos, los menos envejecidos con una proporción por debajo del $8 \%$. Lo más notable es, sin lugar a duda, el incremento que se ha producido en el curso del período 2000-2050 en la distancia que separa el "Norte" del "Oriente" o del "Sur", en cuanto a proporción de personas mayores se refiere (tabla 8). De los 11-12 puntos que se observaban en 2000 , esta diferencia ha pasado a 13 y 15 puntos, respectivamente, si bien, en términos relativos esta diferencia se ha reducido, pasando de cerca de un $70 \%$ a menos de un $50 \%$, es decir, unas diferencias que siguen siendo notables a pesar de la intensificación del proceso tanto en el "Sur" como en el "Oriente".

No obstante, conviene resaltar un fenómeno que podría quedar oculto detrás de lo que se acaba de exponer. Así, de los cerca de 83 millones de nuevos "seniors" del período 2000-2050, unas aproximadas dos terceras partes serán habitantes del "Sur" o del "Oriente", 31 y 22 millones, respectivamente, mientras que el resto, 31 millones, lo será del "Norte". Como consecuencia de esta evolución, el volumen de mayores que residan en 2050 en el "Sur" o el "Oriente", superará ligeramente el del "Norte", con 64 y 63 millones respectivamente, lo que constituye una novedad y exige una nueva lectura del proceso de envejecimiento de los dos lados del Mediterráneo: mayor proporción en el "Norte", efectivos más numerosos en el "Sur" u "Oriente". Paralelamente a este incremento de los ancianos, se produce una contracción de la población menor de 20 años. De tal manera, la población de 0-19 años pasaría de representar un $23,0 \%$ de la población total en 2000 a un 19,8\% en 2050 en el "Norte", mientras que disminuiría desde un $46,6 \%$ a un $26,1 \%$ en el curso del mismo período en el "Sur" y de un 43,2\% a un 25,1\% en el "Oriente". Sin embargo, este doble proceso de envejecimiento por la cúspide y por la base debería ser, en principio, mejor soportado en el "Sur" y el "Oriente" que en el "Norte", en razón de un incremento simultáneo de los potenciales activos en los primeros. Este hecho debería teóricamente permitir una mejor financiación del coste de la 
TABLA 8

EVOLUCIÓN DE LA POBLACIÓN MUNDIAL Y DE LOS PAÍSES DEL MEDITERRÁNEO SEGÚN GRANDE GRUPOS DE EDAD, 2000-2050

\begin{tabular}{|c|c|c|c|c|c|c|c|c|c|}
\hline $2000-2050$ & $\begin{array}{c}\mathrm{P}_{0-19} / \mathrm{P}_{\text {tot }} \\
(\%)\end{array}$ & $\begin{array}{c}\mathrm{P}_{20-64} / \mathrm{P}_{\text {tot }} \\
(\%)\end{array}$ & $\begin{array}{c}\mathrm{P}_{65+} / \mathrm{P}_{\text {tot }} \\
(\%)\end{array}$ & $\begin{array}{c}P_{65+} / P_{0-19} \\
(\%)\end{array}$ & $\begin{array}{c}\mathrm{P}_{65+} / \mathrm{P}_{20-64} \\
(\%)\end{array}$ & $\mathrm{P}_{20-64} / \mathrm{P}_{65+}$ & $\begin{array}{c}\left(\mathrm{P}_{0-19}+\mathrm{P}_{65+}\right) \\
/ \mathrm{P}_{20-64} \\
(\%)\end{array}$ & $\begin{array}{c}\mathrm{P}_{80+} / \mathrm{P}_{\text {tot }} \\
(\%)\end{array}$ & $\begin{array}{c}\mathrm{P}_{80+} / \mathrm{P}_{65 .} \\
(\%)\end{array}$ \\
\hline Planeta & $-13,4$ & 3,9 & 9,4 & 44,7 & 15,5 & $-4,3$ & $-12,8$ & 3,2 & 9,7 \\
\hline Mediterráneo & $-11,7$ & 1,1 & 10,6 & 58,8 & 18,7 & $-2,8$ & $-3,6$ & 4,0 & 9,7 \\
\hline Albania & $-18,3$ & 4,3 & 14,1 & 81,0 & 23,6 & $-4,5$ & $-14,2$ & 5,6 & 16,6 \\
\hline Argelia & $-22,2$ & 8,8 & 13,4 & 64,3 & 21,8 & $-8,5$ & $-30,4$ & 2,8 & 5,4 \\
\hline Bosnia & $-11,6$ & $-7,7$ & 19,3 & 150,4 & 38,6 & $-3,8$ & 23,4 & 8,0 & 19,3 \\
\hline Chipre & $-9,7$ & $-2,3$ & 11,9 & 74,0 & 22,2 & $-2,7$ & 7,0 & 5,0 & 10,5 \\
\hline Croacia & $-4,6$ & $-8,0$ & 12,6 & 81,1 & 28,0 & $-2,0$ & 25,2 & 7,1 & 18,8 \\
\hline Egipto & $-20,5$ & 11,7 & 8,8 & 38,5 & 13,2 & $-6,6$ & $-41,6$ & 1,8 & 6,8 \\
\hline Eslovenia & $-4,2$ & $-12,0$ & 16,2 & 99,9 & 36,9 & $-2,8$ & 37,3 & 8,2 & 18,4 \\
\hline España & $-1,8$ & $-13,2$ & 15,0 & 84,3 & 38,1 & $-2,1$ & 43,6 & 7,5 & 13,1 \\
\hline Francia & $-3,7$ & $-7,1$ & 10,8 & 60,1 & 24,9 & $-1,7$ & 23,8 & 7,4 & 18,1 \\
\hline Grecia & $-3,9$ & $-10,9$ & 14,8 & 97,8 & 35,1 & $-2,1$ & 35,2 & 7,8 & 16,8 \\
\hline Israel & $-11,7$ & 2,5 & 9,2 & 49,1 & 15,8 & $-2,5$ & $-8,3$ & 4,0 & 10,9 \\
\hline Italia & $-1,7$ & $-13,2$ & 14,8 & 91,1 & 38,4 & $-1,9$ & 43,6 & 9,2 & 17,3 \\
\hline Líbano & $-17,2$ & 4,7 & 12,5 & 67,3 & 20,6 & $-4,8$ & $-15,2$ & 3,4 & 9,8 \\
\hline Libia & $-20,4$ & 6,2 & 14,2 & 63,6 & 24,0 & $-12,1$ & $-20,9$ & 3,0 & 7,3 \\
\hline Malta & $-10,5$ & $-6,6$ & 17,0 & 129,0 & 34,2 & $-3,0$ & 20,3 & 7,1 & 13,2 \\
\hline Marruecos & $-20,2$ & 8,4 & 11,9 & 56,1 & 18,9 & $-7,2$ & $-28,5$ & 2,7 & 7,8 \\
\hline Serbia & $-6,3$ & $-3,8$ & 10,1 & 62,0 & 19,9 & $-2,0$ & 11,7 & 4,6 & 14,6 \\
\hline Siria & $-26,6$ & 16,2 & 10,4 & 44,5 & 15,5 & $-10,0$ & $-62,2$ & 2,0 & 6,0 \\
\hline T.Palestinos & $-21,5$ & 17,7 & 3,9 & 14,7 & 4,1 & $-3,6$ & $-77,5$ & 0,9 & 3,4 \\
\hline Túnez & $-18,8$ & 4,3 & 14,5 & 78,6 & 24,5 & $-5,7$ & $-14,2$ & 3,8 & 8,8 \\
\hline Turquía & $-17,4$ & 4,2 & 13,1 & 65,1 & 22,0 & $-7,1$ & $-13,6$ & 3,2 & 10,8 \\
\hline Med. Norte & $-3,2$ & $-10,2$ & 13,4 & 79,2 & 32,2 & $-2,0$ & 33,6 & 7,9 & 16,4 \\
\hline Med. Sur & $-20,5$ & 9,8 & 10,8 & 48,8 & 16,8 & $-7,2$ & $-34,0$ & 2,3 & 6,9 \\
\hline Med. Oriente & $-18,1$ & 6,7 & 11,5 & 54,3 & 18,5 & $-6,4$ & $-22,2$ & 2,9 & 9,2 \\
\hline
\end{tabular}

Fuente: United Nations, World Population Prospects, the 2008 Revision, www.un.org

inactividad, un lujo desde muchos aspectos. Simultáneamente, se produciría una intensa disminución de éstos en el "Norte", desde un 60,5\% hasta un $50,2 \%$, entre las dos fechas. No sólo el número de activos por "senior" se ha reducido notablemente tanto en el "Norte" cuya ratio ha pasado de cerca 
de 4 a menos de 2, como en el "Sur" o el "Oriente", cuyas ratios lo han hecho de 11 y 10, respectivamente, a 4 sino que, además, el déficit de nacimientos ya no permite compensar el incremento del número de ancianos. Simultáneamente, el retroceso de la mortalidad ha supuesto una transformación de la estructura de la población mayor en la cual los "super seniors" empiezan a reivindicar una posición cada vez más importante y, de hecho, la ocupan.

En 2050, el peso de las de personas de 80 o más años en el conjunto del Mediterráneo, $6 \%$, varía de forma bastante acusada según la zona: del doble en el "Norte", a la mitad en el "Sur" o el "Oriente", es decir, una relación de 4 a 1 entre la primera y las demás zonas. Contrariamente a lo que se observaba en el caso de los "seniors", en el "Norte", 23,9 millones, residen cerca de dos veces más de los que se podría denominar "super seniors", que en el "Sur" o el "Oriente" reunidos (7,0 y 5,6 millones, respectivamente), lo que supone un sobre envejecimiento de mayor intensidad en el "Norte", 38,3\% de personas de 80 o más años entre aquellas de 65 o más, que en el "Sur", 18,8\%, o el "Oriente", 20,9\%, con sus consecuencias previsibles: crecimiento proporcional de los costes de atención socio-sanitaria hacia estas personas, aumento de la demanda de personal tanto médico como social de cuidados y atención con una formación adecuada, incremento de la demanda de plazas en instituciones de acogida, etc. En definitiva, los problemas que se perciben en un futuro que no es muy lejano, tienen que ver con la demanda de servicios directamente ligados a las características físicas y médicas de una población de "super seniors" en fuerte incremento.

Las profundas transformaciones que se han producido en las estructuras por edad de la población del Mediterráneo (ver gráfico 2) han conducido éstas a un intenso envejecimiento bajo los efectos combinados de una disminución de los jóvenes y de un incremento de los mayores. Se ha igualmente desarrollado un envejecimiento del envejecimiento, es decir, un incremento tanto absoluto como relativo de la población muy mayor, lo cual debería modificar sensiblemente, tanto el análisis del fenómeno general del envejecimiento, como las posibles soluciones a su desarrollo, si éstas existen.

El envejecimiento demográfico no es exclusivo de los países más ricos y, de hecho, la totalidad de la cuenca del Mediterráneo está sometida a sus efectos, aunque en niveles y ritmos diferentes, con una visibilidad más o menos importante, en condiciones más o menos favorables, pero ya se volverá sobre estos aspectos ulteriormente. 
GRÁFICO 2

EVOLUCIÓN DE LA PIRÁMIDE DE EDAD DE LA POBLACIÓN MEDITERRÁNEA, $1950-2050$

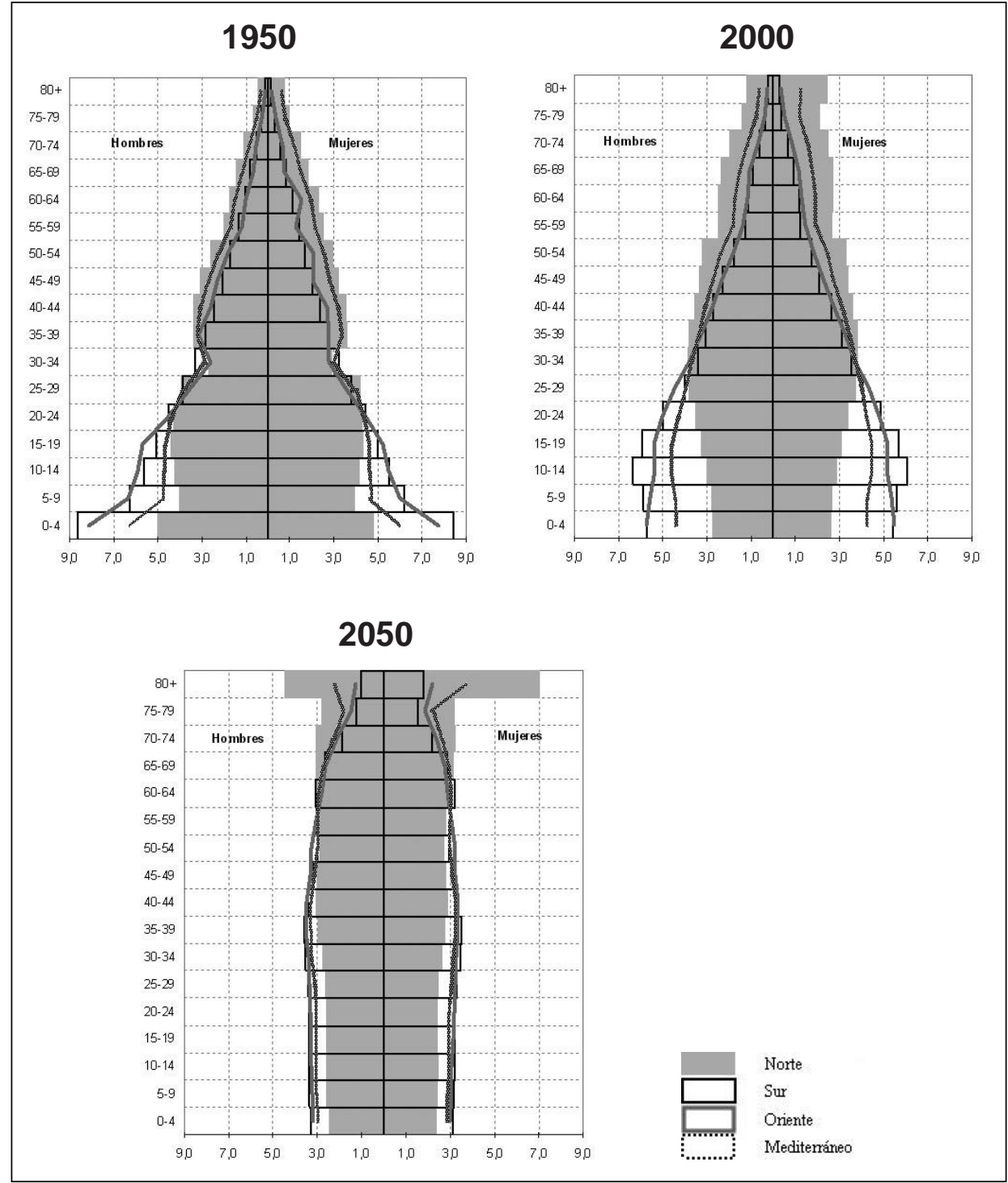

Fuente: United Nations, World Population Prospects, the 2008 Revision, www.un.org 
LOS FACTORES DE LOS CAMBIOS

¿Cuáles son las razones de los cambios que se han producido y de las distintas evoluciones observadas o que deberían producirse en un futuro próximo, si las hipótesis formuladas por Naciones Unidas se materializasen?

En primer lugar, conviene precisar que hemos utilizado los datos del World Population Prospects, publicados por Naciones Unidas en 2009, en su última revisión de 2008. Aunque no parezca necesario realizar, en el marco de este artículo, un análisis fino y profundo, ni de los datos utilizados, ni de las perspectivas elaboradas por la $\mathrm{ONU}^{6}$, parece sin embargo conveniente resaltar que las hipótesis de convergencia de comportamientos, esencialmente reproductivos pero no únicamente, que consisten básicamente en aumentar la fecundidad en los países con baja fecundidad y en reducirla en aquellos en los cuales ésta es elevada, no es convincente, sobre todo en su esencia puramente automática y al margen de cualquier tipo de evoluciones pasadas y de las características propias de cada país. Una vez dicho esto, también debe notarse que los datos utilizados son, para la mayor parte de ellos, datos retrospectivos que, consecuentemente, reflejan la evolución pasada de manera bastante clara.

La observación pasada permite comprobar los profundos cambios que se han producido a lo largo de estos casi sesenta últimos años en la mayoría de las poblaciones del planeta e, igualmente, alrededor del Mediterráneo: la mortalidad y la fecundidad han experimentado una intensa reducción de su intensidad mientras que las migraciones cambiaban de dirección y de signo. Se ha asistido a una verdadera transformación de los comportamientos demográficos de poblaciones muy diversas los cuales, a su vez, han modificado las estructuras demográficas las más elementales como, por ejemplo, la distribución por edad. No cabe tampoco ninguna duda de que otros cambios acompañaran al envejecimiento demográfico que se extiende a toda la cuenca del Mediterráneo, cambios sociales, económicos, políticos, etc., los cuales configuran un futuro bastante borroso, a pesar de que, a veces, se plantee un porvenir de una nitidez ficticia que sólo procede de una proyección errónea en un marco invariable, tan difícil es discernir cambios si no globales, por lo menos demasiado parciales y separados de su contexto y de su entorno. La mortalidad es el primero de los factores que permiten explicar, simultáneamente, el proceso de envejecimiento y las diferencias existentes (mapa 4 y tabla 9).

\footnotetext{
${ }^{6}$ Más allá del hecho de que no se trata del tema de este artículo, este tipo de análisis ya ha sido llevado a cabo. Ver, por ejemplo, Keilman, 1998 o Kupiszewski et al., 2005.
} 


\section{MAPA 4}

EVOLUCIÓN DE LA ESPERANZA DE VIDA AL NACIMIENTO DE LAS MUJERES. PAÍSES DEL MEDITERRÁNEO, 1950-2050

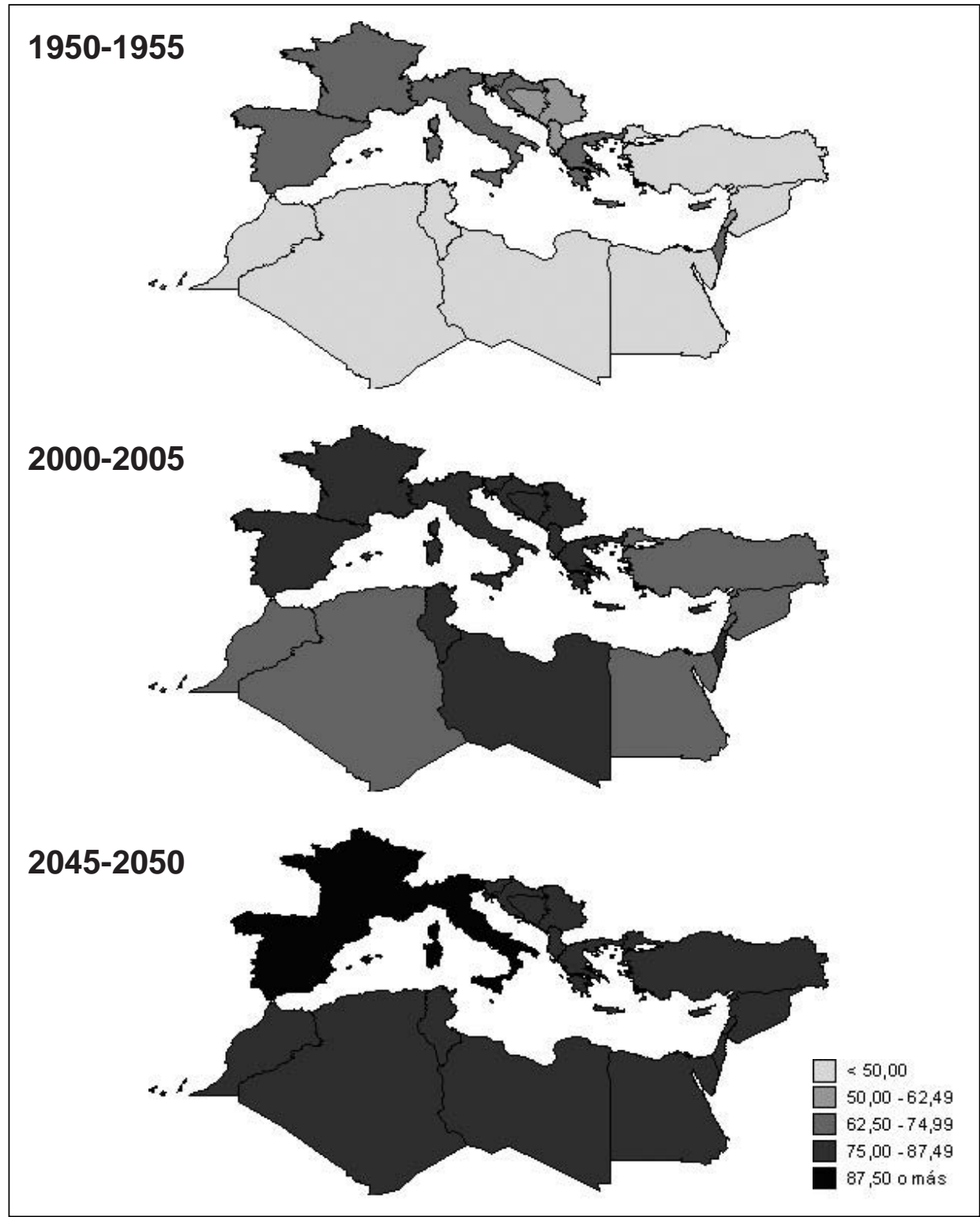

Fuente: United Nations, World Population Prospects, the 2008 Revision, www.un.org 
TABLA 9

EVOLUCIÓN DE LA ESPERANZA DE VIDA AL NACIMIENTO DE LAS MUJERES DE LA POBLACIÓN MUNDIAL Y DE LOS PAÍSES DEL MEDITERRÁNEO, $1950-2050$

\begin{tabular}{|c|c|c|c|c|c|c|}
\hline $\mathrm{e}_{0 \mathrm{muj}}$ & $1950-1955$ & $2000-2005$ & $2045-2050$ & $\begin{array}{l}1950-1955 \\
2045-2050\end{array}$ & $\begin{array}{l}1950-1955 \\
2000-2005\end{array}$ & $\begin{array}{l}2000-2005 \\
2045-2050\end{array}$ \\
\hline Planeta & 48,0 & 68,6 & 77,9 & 29,9 & 20,6 & 9,3 \\
\hline Mediterráneo & 56,7 & 77,4 & 83,9 & 27,2 & 20,7 & 6,6 \\
\hline Med. Norte & 64,1 & 80,1 & 85,8 & 21,7 & 16,1 & 5,7 \\
\hline Albania & 56,1 & 79,0 & 84,3 & 28,2 & 22,9 & 5,3 \\
\hline Bosnia & 54,8 & 77,2 & 82,5 & 27,7 & 22,4 & 5,3 \\
\hline Croacia & 63,2 & 78,4 & 84,5 & 21,3 & 15,2 & 6,1 \\
\hline Eslovenia & 68,1 & 80,3 & 86,7 & 18,6 & 12,2 & 6,4 \\
\hline España & 66,3 & 83,1 & 88,0 & 21,7 & 16,8 & 4,9 \\
\hline Francia & 69,9 & 83,1 & 88,9 & 19,0 & 13,2 & 5,8 \\
\hline Grecia & 67,5 & 80,4 & 86,6 & 19,1 & 12,9 & 6,2 \\
\hline Italia & 68,1 & 83,1 & 88,4 & 20,3 & 15,0 & 5,3 \\
\hline Malta & 67,7 & 80,8 & 86,2 & 18,5 & 13,1 & 5,4 \\
\hline Serbia & 58,8 & 75,6 & 81,7 & 22,9 & 16,8 & 6,1 \\
\hline Med. Sur & 44,2 & 73,1 & 81,2 & 37,1 & 28,9 & 8,1 \\
\hline Argelia & 44,2 & 72,2 & 80,9 & 36,7 & 28,0 & 8,7 \\
\hline Egipto & 43,7 & 70,7 & 79,8 & 36,1 & 27,0 & 9,1 \\
\hline Libia & 43,9 & 75,7 & 82,6 & 38,7 & 31,8 & 6,9 \\
\hline Marruecos & 43,9 & 71,8 & 80,8 & 36,9 & 27,9 & 9,0 \\
\hline Túnez & 45,1 & 75,1 & 82,1 & 37,0 & 30,0 & 7,0 \\
\hline Med. Oriente & 55,0 & 76,4 & 83,1 & 28,1 & 21,4 & 6,7 \\
\hline Chipre & 69,0 & 81,4 & 86,0 & 17,0 & 12,4 & 4,6 \\
\hline Israel & 66,4 & 81,7 & 87,3 & 20,9 & 15,3 & 5,6 \\
\hline Líbano & 57,7 & 73,2 & 80,8 & 23,1 & 15,5 & 7,6 \\
\hline Siria & 47,2 & 74,9 & 82,1 & 34,9 & 27,7 & 7,2 \\
\hline T. Palestinos & 44,3 & 73,9 & 81,5 & 37,2 & 29,6 & 7,6 \\
\hline Turquía & 45,2 & 73,3 & 80,9 & 35,7 & 28,1 & 7,6 \\
\hline
\end{tabular}

Nota: Los datos relativos al conjunto del Mediterráneo, al "Norte", "Sur" y "Oriente", son las medias ponderadas del conjunto de los países que los componen.

Fuente: United Nations, World Population Prospects, the 2008 Revision, www.un.org 
En primer lugar, los mapas muestran tanto las diferencias iniciales como las ganancias en términos de esperanzas de vida al nacimiento de las mujeres ${ }^{7}$ que han tenido lugar a lo largo de los 100 años considerados. En 1950-1955 los mapas muestran unos colores pálidos, aunque con diferencias profundas entre "Norte", "Sur" y "Oriente" (64,1, 44,2 y 55,0 años, respectivamente). En el primero, únicamente tres países (Albania, Bosnia y Serbia) tienen una esperanza de vida al nacimiento de menos de 60 años, mientras que en el segundo sólo en tres países (Chipre, Israel y Líbano) las mujeres tienen una esperanza de vida al nacer que supera los 55 años. Por otro lado, cerca de 26 años separan las esperanzas de vida de las mujeres de Francia y de Egipto.

Los progresos de la medicina, una cobertura social más amplia, una mejora del nivel de vida, etc., han permitido ganancias bastante sustanciales, en término de años de vida, entre la mitad y el final del siglo $\mathrm{xx}^{8}$. Estos se traducen por un incremento general de la esperanza de vida al nacimiento y en una reducción simultánea de las diferencias entre el "Norte", el "Sur" y el "Oriente" (80,1, 76,4 y 73,1 años, respectivamente), es decir, por unas ganancias mucho más importantes en las regiones menos desarrolladas que en las otras. No sólo la distancia entre los extremos se ha reducido (12,4 años entre España, Francia o Italia y Egipto), sino que además, en 2000-2005, la esperanza de vida al nacimiento más baja, la de las mujeres egipcias, es más elevada que la de las francesas en 1950-1955. El principal factor del envejecimiento por la cima, la reducción de la mortalidad, ha conocido un auge decisivo y se ha difundido a lo largo y ancho del Mediterráneo, a la vez que se estrechaban las diferencias de sus diversos componentes. El resultado no se ha hecho esperar: "Sur" y "Oriente" han visto incrementarse el número de sus mayores a pesar de que su peso en la población total haya sido frenado, contenido, casi ocultado por el intenso incremento de los jóvenes en el curso de la segunda mitad del siglo Xx, consecuencia tanto de la alta fecundidad en esta orilla del Mediterráneo, como de su todavía muy joven estructura por edad.

A mediados del siglo xxI, el mapa de la esperanza de vida femenina muestra una cierta homogeneidad. Así, las diferencias se han reducido hasta lograr valores casi increíbles: 4,5 y 2,7 años entre el "Norte" y el "Sur" y el "Oriente", res-

${ }^{7}$ Se ha elegido la esperanza de vida al nacimiento de las mujeres en razón tanto de su calidad como indicador de la mortalidad, como de las escasas diferencias que habrían resultado de haber escogido la de los hombres o la de ambos sexos.

${ }^{8}$ No se tiene la pretensión de describir aquí la evolución de la mortalidad ni de sus causas, pero las personas interesadas pueden consultar algunos autores como Omran, 1971; McKeown, 1976; Rogers y Hackenber, 1987; Livi-Bacci, 1988; Frenk et al., 1991; Mackenbach, 1996; Meslé y Vallin, 1997, entre otros. 
pectivamente, contra 19,9 y 9,1 años, respectivamente, un siglo antes. Lo increíble no resulta de la impresión de que estas diferencias no se puedan alcanzar, sino, más bien, de cierta cautela a la que invitan las hipótesis formuladas por Naciones Unidas. Porque, efectivamente, de esto se trata aquí: de las hipótesis de evolución futura de la mortalidad propuestas por Naciones Unidas y del proceso de convergencia que presuponen. Por un lado, invitan a pensar que las esperanzas de vida más altas tienen escasas posibilidades de aumentar en el futuro y que, por otro lado, las condiciones que han permitido lograr estos niveles altos son exportables en poblaciones que parecen todavía lejos de alcanzar, no estas mortalidades reducidas, sino un alto nivel de desarrollo económico y una universalización de los sistemas de salud y de pensiones, entre otras cosas. Estos elementos son primordiales para poder enfrentarse a otros desafíos que se avecinan como son el proceso de desertización, los efectos del cambio climático, el acceso al agua, la emigración, la dependencia económica, etc. y que se añadirán a las consecuencias probablemente muy delicadas aunque, con toda seguridad, también rápidas a la vez que totalmente previsibles, del envejecimiento demográfico.

Las importantes ganancias en términos de años de vida que se han producido en los países denominados en desarrollo, permiten entender el intenso desarrollo del envejecimiento demográfico observado en el "Sur" y el "Oriente". Sin embargo, el cuadro no estaría completo si no se añadiese el descenso de la fecundidad, una disminución que aunque menos uniforme que el de la mortalidad, ha situado el conjunto del contorno mediterráneo en una perspectiva de envejecimiento generalizado, aunque en niveles y ritmos diferentes.

A mediados del siglo pasado, el Mediterráneo presenta no sólo una fecundidad elevada e idéntica a la del conjunto del planeta, 4,9 hijos por mujer en ambos casos, sino también una gran diversidad de comportamientos reproductivos a lo largo y ancho de su geografía (mapa 5 y tabla 10). Una vez más, "Norte", "Sur" y "Oriente" están alejados y esta vez por 3,6 y 2,5 hijos entre el primero y los siguientes, con 3,3, 6,9 y 5,9 hijos por mujer, respectivamente. Más de 5 hijos por mujer separan la fecundidad de los territorios Palestinos de la de Grecia, los niveles extremos en 1950-1955, fecha en la cual todas las poblaciones del Mediterráneo aseguraban ampliamente su reemplazo.

Cincuenta años más tarde las cosas son muy diferentes ${ }^{9}$. En 2000-2005, la

\footnotetext{
${ }^{9}$ Como en el caso anterior, se sugiere a las personas interesadas en el descenso de la fecundidad consultar algunos autores como Davis, 1963; Coale, 1973; Caldwell, 1978; Höhn y Mackensen, 1980; Becker, 1987; Leibenstein, 1981; Lesthaeghe, 1980 y 1983; Lesthaeghe y Wilson, 1982; Leasure, 1982; Davis, Bernstam y Ricardo-Campbell, 1986; Keyfitz, 1986; Chesnais, 1999; Lesthaeghe y Willems, 1999; Bachrach, 2001; Bongaarts, 2001; Van de Kaa, 2001; Kohler et al., 2002; Delgado, 2003; Frejka, T. y Sardon, J.-P., 2004, entre otros.
} 
MAPA 5

EVOLUCIÓN DEL ÍNDICE SINTÉTICO DE FECUNDIDAD.

PAÍSES DEL MEDITERRÁNEO, 1950-2050

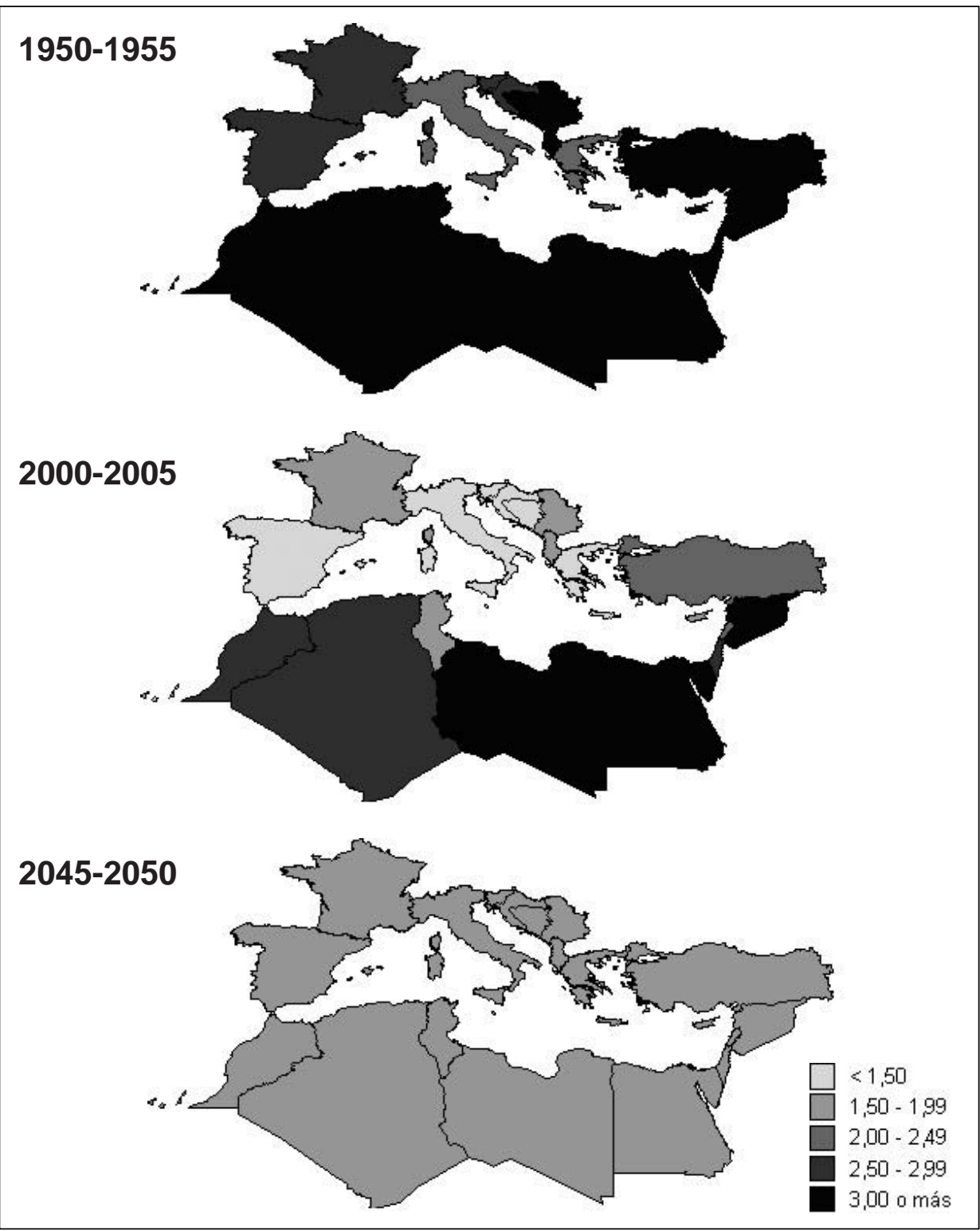

Fuente: United Nations, World Population Prospects, the 2008 Revision, www.un.org 
TABLA 10

EVOLUCIÓN DEL ÍNDICE SINTÉTICO DE FECUNDIDAD DE LA POBLACIÓN MUNDIAL Y DE LOS PAÍSES DEL MEDITERRÁNEO, 1950-2050

\begin{tabular}{|c|c|c|c|c|c|c|}
\hline ISF & $1950-1955$ & $2000-2005$ & $2045-2050$ & $\begin{array}{l}1950-1955 \\
2045-2050\end{array}$ & $\begin{array}{l}1950-1955 \\
2000-2005\end{array}$ & $\begin{array}{l}2000-2005 \\
2045-2050\end{array}$ \\
\hline Planeta & 4,9 & 2,7 & 2,0 & $-2,9$ & $-2,3$ & $-0,7$ \\
\hline Mediterráneo & 4,9 & 2,2 & 1,8 & $-3,1$ & $-2,7$ & $-0,3$ \\
\hline Med. Norte & 3,3 & 1,5 & 1,8 & $-1,6$ & $-1,9$ & 0,3 \\
\hline Albania & 5,6 & 2,0 & 1,9 & $-3,8$ & $-3,6$ & $-0,1$ \\
\hline Bosnia & 4,8 & 1,3 & 1,6 & $-3,2$ & $-3,5$ & 0,3 \\
\hline Croacia & 2,8 & 1,4 & 1,8 & $-0,9$ & $-1,4$ & 0,5 \\
\hline Eslovenia & 2,8 & 1,2 & 1,8 & $-1,0$ & $-1,6$ & 0,6 \\
\hline España & 2,6 & 1,3 & 1,9 & $-0,7$ & $-1,3$ & 0,6 \\
\hline Francia & 2,7 & 1,9 & 1,9 & $-0,9$ & $-0,9$ & 0,0 \\
\hline Grecia & 2,3 & 1,3 & 1,8 & $-0,5$ & $-1,0$ & 0,5 \\
\hline Italia & 2,4 & 1,3 & 1,7 & $-0,6$ & $-1,1$ & 0,5 \\
\hline Malta & 4,1 & 1,5 & 1,6 & $-2,5$ & $-2,7$ & 0,2 \\
\hline Serbia & 3,2 & 1,7 & 1,9 & $-1,4$ & $-1,5$ & 0,1 \\
\hline Med. Sur & 6,9 & 2,6 & 1,9 & $-5,1$ & $-4,3$ & $-0,8$ \\
\hline Argelia & 7,3 & 2,5 & 1,9 & $-5,4$ & $-4,8$ & $-0,7$ \\
\hline Egipto & 6,4 & 3,2 & 1,9 & $-4,5$ & $-3,2$ & $-1,2$ \\
\hline Libia & 6,9 & 3,0 & 1,9 & $-5,0$ & $-3,8$ & $-1,2$ \\
\hline Marruecos & 7,2 & 2,5 & 1,9 & $-5,3$ & $-4,7$ & $-0,7$ \\
\hline Túnez & 6,9 & 2,0 & 1,9 & $-5,1$ & $-5,0$ & $-0,1$ \\
\hline Med. Oriente & 5,9 & 3,0 & 1,9 & $-3,9$ & $-2,9$ & $-1,1$ \\
\hline Chipre & 3,7 & 1,6 & 1,9 & $-1,9$ & $-2,1$ & 0,2 \\
\hline Israel & 4,2 & 2,9 & 1,9 & $-2,3$ & $-1,3$ & $-1,0$ \\
\hline Líbano & 5,7 & 2,1 & 1,9 & $-3,9$ & $-3,7$ & $-0,2$ \\
\hline Siria & 7,3 & 3,6 & 1,9 & $-5,5$ & $-3,7$ & $-1,8$ \\
\hline T. Palestinos & 7,4 & 5,6 & 2,4 & $-5,0$ & $-1,8$ & $-3,3$ \\
\hline Turquía & 6,9 & 2,2 & 1,9 & $-5,1$ & $-4,7$ & $-0,4$ \\
\hline
\end{tabular}

Nota: Los datos relativos al conjunto del Mediterráneo, al "Norte", "Sur" y "Oriente", son las medias ponderadas del conjunto de los países que los componen.

Fuente: United Nations, World Population Prospects, the 2008 Revision, www.un.org 
fecundidad ha disminuido de cerca de 3 hijos por mujer en el conjunto del Mediterráneo y alcanza 2,2 hijos por mujer, es decir, una diferencia de 0,5 hijos por mujer con respecto al conjunto del planeta cuyo índice sintético de fecundidad alcanza los 2,7 hijos por mujer en la misma fecha. En términos absolutos, la diferencia entre el "Norte", el "Sur" y el "Oriente", se ha reducido a 1,5 hijos por mujer en lugar de los cerca de 3 del período anterior. A pesar de ello, descensos intensos de la fecundidad se observan tanto en el "Norte", como en el "Sur" o el "Oriente". De tal modo que la fecundidad se ha reducido en cerca de un $73 \%$ en Bosnia y de un $72 \%$ en Túnez. No obstante, los descensos son menores cuanto más bajos eran los niveles en 1950-1955. Desde este punto de vista, la fecundidad de los países árabes ha conocido una importante reducción que podría significar una transformación social mucho más profunda de lo que podría parecer a primera vista (Fargues, 1986 y 1988; Faour, 1989; Obermeyer, 1992). A pesar de estas intensas disminuciones, la diferencia entre los países de menor y de mayor fecundidad se mantiene muy elevada: Eslovenia, 1,2, y Territorios Palestinos, 5,6 hijos por mujer, respectivamente. ¿Qué decir, sin embargo, con respecto a las hipótesis seráficas de Naciones Unidas que proponen un acercamiento futuro de los niveles de fecundidad de los diversos países del Mediterráneo? De tal modo que se produciría, simultáneamente, una recuperación salvadora de la agotada fecundidad del "Norte" y un retroceso tranquilizador de la desmedida fecundidad del "Sur" y de "Oriente". No parece, sin embargo, muy aventurado adelantar una permanencia de las diferencias significativas entre el "Norte" y el "Sur" o el "Oriente", y ello a pesar de una posible disminución de éstas. Las razones de este pronóstico se basan en la existencia de diferencias sociales, económicas y religiosas que no parecen en medida de desaparecer en un futuro próximo, así como en la dificultad en poder imaginar un mundo constituido de pueblos idénticos, indiferenciados, gemelos o clónicos.

Las migraciones constituyen el tercer componente, tanto de la dinámica demográfica como de la transformación de las estructuras demográficas. Los movimientos migratorios del Mediterráneo han jugado y siguen jugando una función determinante en el seno de las migraciones internacionales, tanto en razón de la diversidad de las situaciones que se observan en él, como de los volúmenes involucrados. Por otra parte, el espacio mediterráneo no ha escapado a los profundos cambios que, desde la segunda mitad del siglo xx, como lo resalta Arango (2003), han marcado el conjunto de las migraciones internacionales. De tal modo que coexisten países "tradicionales" de inmigración como Francia, con países de emigración como aquellos pertenecientes a la ribera africana o, también, países expulsores que se han 
convertido en receptores como España, Grecia o Italia. A estos últimos se añaden otros como Bosnia, Croacia o los Territorios Palestinos, cuyos movimientos migratorios se explican, en parte, por los conflictos armados de los que han sido testigos.

Considerado en su conjunto, el Mediterráneo presenta una tasa anual de migración neta negativa entre 1950 y 1990 (gráfico 3). En el curso de estos años, el saldo migratorio ${ }^{10}$ fue negativo en casi 7 millones de personas, con una tasa anual de migración neta más baja, $-1,2 \%$, correspondiente al período 1965-1970, mientras que la más elevada, $-0,1 \%$, se observaba en el quinquenio 1980-1985. La década siguiente constituye el paso del conjunto mediterráneo de región principalmente expulsora a una zona mayoritariamente de acogida. En este contexto, la tasa anual de migración neta más elevada del período 1990-2005, en el curso del cual habrían llegado más de 4,5 millones de inmigrantes netos, se situaría en el período 2000-2005, con un $+1,7 \%$ o.

\section{GRÁFICO 3}

\section{EVOLUCIÓN DE LAS TASAS ANUALES DE MIGRACIÓN NETA (EN POR MIL).} PAÍSES DEL MEDITERRÁNEO, 1950-2050

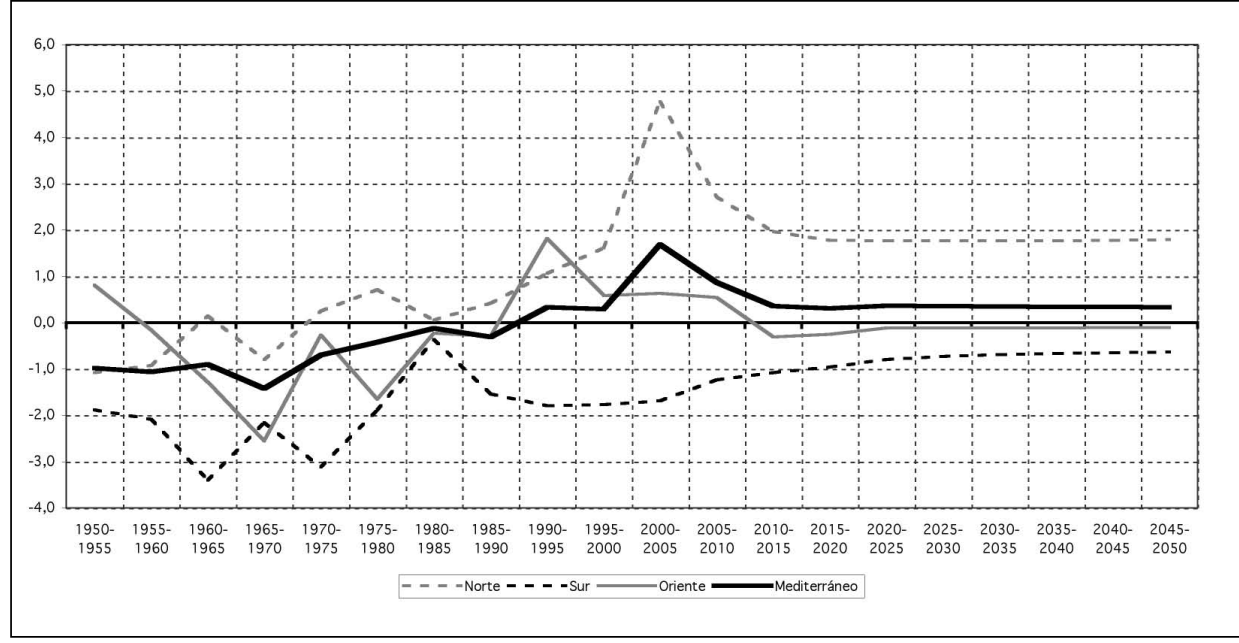

Fuente: United Nations, World Population Prospects, the 2008 Revision, www.un.org

${ }^{10}$ Los saldos migratorios han sido calculados mediante el método de los residuos y han permitido obtener las tasas anuales de migración neta. 
Sin embargo y como en los casos anteriores de la estructura por edad, de la mortalidad o de la fecundidad, los movimientos migratorios muestran diferencias significativas entre "Norte", "Sur" y "Oriente". De tal modo, los saldos migratorios del conjunto del "Sur" son negativos a lo largo del período 1950-2050, con valores que oscilan entre un -3,6\%o (1960-1965) y un -0,5\%o (1980-1985). Por su parte, tanto el "Norte" como el "Oriente" presentan una mayor versatilidad. Así, el primero presenta valores negativos hasta 1965-1970 (positivos en 1960-1965), antes de hacer muestra de una capacidad de atracción bastante elevada que sitúa su tasa anual de migración neta en $+5,0 \%$ o en 2000-2005. El segundo, expulsor neto entre 1955 y 1990, invierte el signo de sus intercambios entre 1990 y 2010, Naciones Unidas volviendo a situarle en valores negativos a partir de esta fecha. Lo que muestran estos datos, es la profunda mutación que ha alcanzado el Mediterráneo desde el punto de vista migratorio y que se materializa bajo la forma de un cambio tanto en la procedencia y el destino de los migrantes en el curso del tiempo, como por la transformación de determinados países, de zonas de salida en zonas de acogida.

En 1950-1955 (mapa 6 y tabla 11), es decir, al inicio del período considerado, el Mediterráneo puede considerarse como una cuenca emigratoria, si se tiene en cuenta que tan sólo cuatro países (Israel, Francia, Serbia y Albania ${ }^{11}$ ) muestran tasas de migración neta positivas, mientras que los dieciocho restantes son expulsores netos, con la excepción de Marruecos cuyo saldo es nulo. Esta tendencia emigratoria va a prolongarse hasta los años setenta. Entre 1950 y 1970, todos los países euro mediterráneos, excepto Francia, presentan tasas de migración neta negativas. Francia alcanzó una tasa de $+6,2 \%$ en 1960-1965, su valor más elevado de todo el período de estudio, lo que representa un volumen de cerca de 1,5 millones de entradas netas en el curso de estos únicos cinco años. Por el contrario, otros países euro mediterráneos fueron testigos de importantes flujos de salida dirigidos principalmente hacia el continente americano pero también, aunque en menor medida, hacia el norte de África y Europa occidental. Italia y España ilustran perfectamente este movimiento con tasas de migración neta negativas. Simultáneamente y como consecuencia de la descolonización (Faron y George, 1999), entre 1950 y 1970, numerosas personas originarias de distintas colonias van a establecerse en las antiguas potencias coloniales como es el caso, por ejemplo, de los Argelinos en Francia (Solé et al., 2000).

\footnotetext{
${ }^{11}$ Es posible que los saldos positivos que presenta Albania resulten de la combinación de estadísticas imperfectas y que deban considerarse, consecuentemente, con cierta cautela.
} 


\section{MAPA 6}

TASA ANUAL DE MIGRACIÓN NETA EN 1950-1955, 1975-1980 Y 2000-2005

(EN POR MIL). PAÍSES DEL MEDITERRÁNEO

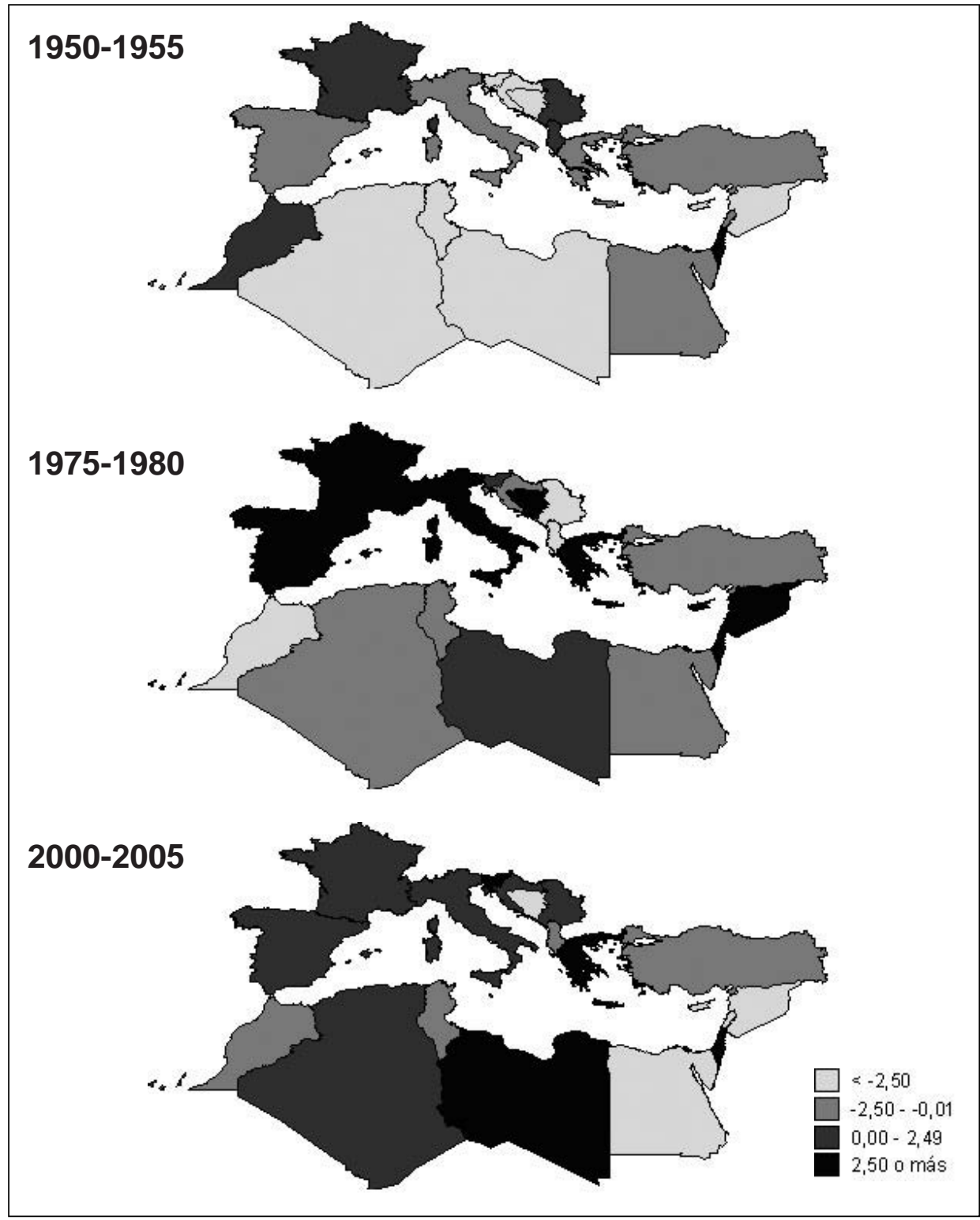

Fuente: United Nations, World Population Prospects, the 2008 Revision, www.un.org

Estudios Geográficos, Vol. LXX, 267, pp. 661-705, julio-diciembre 2009 ISSN: 0014-1496, eISSN: 1988-8546, doi: 10.3989/estgeogr.0469 
TABLA 11

EVOLUCIÓN DE LAS TASAS ANUALES DE MIGRACIÓN NETA (EN POR MIL). PAÍSES DEL MEDITERRÁNEO, 1050-2050

\begin{tabular}{|c|c|c|c|c|c|c|}
\hline TAMN (\%o) & $1950-1955$ & $2000-2005$ & $2045-2050$ & $\begin{array}{l}1950-1955 \\
2045-2050\end{array}$ & $\begin{array}{l}1950-1955 \\
2000-2005\end{array}$ & $\begin{array}{l}2000-2005 \\
2045-2050\end{array}$ \\
\hline Planeta & 0,0 & 0,0 & 0,0 & 0,0 & 0,0 & 0,0 \\
\hline Mediterráneo & $-0,7$ & 1,9 & 0,5 & 1,1 & 2,6 & $-1,4$ \\
\hline Med. Norte & $-0,5$ & 4,9 & 2,0 & 2,6 & 5,5 & $-2,9$ \\
\hline Albania & 0,9 & $-6,4$ & $-2,8$ & $-3,8$ & $-7,3$ & 3,6 \\
\hline Bosnia & $-3,0$ & 3,2 & $-0,1$ & 2,9 & 6,2 & $-3,3$ \\
\hline Croacia & $-2,6$ & $-0,5$ & 0,6 & 3,1 & 2,0 & 1,1 \\
\hline Eslovenia & $-3,9$ & 2,1 & 2,5 & 6,4 & 6,0 & 0,4 \\
\hline España & $-1,8$ & 12,0 & 2,9 & 4,7 & 13,8 & $-9,1$ \\
\hline Francia & 1,3 & 2,5 & 1,5 & 0,2 & 1,2 & $-1,1$ \\
\hline Grecia & $-2,0$ & 2,7 & 2,8 & 4,7 & 4,7 & 0,1 \\
\hline Italia & $-0,9$ & 6,1 & 2,6 & 3,5 & 6,9 & $-3,4$ \\
\hline Malta & $-17,3$ & 4,6 & 1,0 & 18,2 & 21,8 & $-3,6$ \\
\hline Serbia & 0,9 & $-6,7$ & 0,1 & $-0,9$ & $-7,7$ & 6,8 \\
\hline Med. Sur & $-2,1$ & $-1,4$ & $-0,6$ & 1,5 & 0,7 & 0,8 \\
\hline Argelia & $-6,3$ & $-0,9$ & $-0,3$ & 6,0 & 5,4 & 0,6 \\
\hline Egipto & $-0,4$ & $-0,8$ & $-0,6$ & $-0,2$ & $-0,4$ & 0,2 \\
\hline Libia & $-8,0$ & 0,5 & 0,5 & 8,4 & 8,5 & 0,0 \\
\hline Marruecos & 0,0 & $-3,7$ & $-1,2$ & $-1,2$ & $-3,7$ & 2,6 \\
\hline Túnez & $-5,8$ & $-1,7$ & $-0,3$ & 5,5 & 4,1 & 1,4 \\
\hline Med. Oriente & 0,8 & 1,0 & 0,0 & $-0,8$ & 0,2 & $-1,0$ \\
\hline Chipre & $-3,5$ & 7,1 & 4,1 & 7,6 & 10,7 & $-3,0$ \\
\hline Israel & 39,2 & 3,4 & 0,6 & $-38,6$ & $-35,8$ & $-2,8$ \\
\hline Líbano & $-0,1$ & 5,0 & $-0,9$ & $-0,8$ & 5,1 & $-5,9$ \\
\hline Siria & $-3,7$ & 3,4 & $-0,3$ & 3,4 & 7,0 & $-3,6$ \\
\hline T. Palestinos & $-13,5$ & 0,9 & $-0,5$ & 12,9 & 14,3 & $-1,4$ \\
\hline Turquía & $-0,2$ & $-0,2$ & 0,0 & 0,2 & 0,0 & 0,2 \\
\hline
\end{tabular}

Nota: Los datos relativos al conjunto del Mediterráneo, al "Norte", "Sur" y "Oriente", son las medias ponderadas del conjunto de los países que los componen.

Fuente: United Nations, World Population Prospects, the 2008 Revision, www.un.org 
Este modelo migratorio va a prolongarse hasta el momento de la Guerra del Yom Kippur en 1973. Efectivamente, los problemas económicos y el importante incremento del paro ligados a la primera gran crisis del petróleo, van a conducir a políticas migratorias restrictivas en Europa occidental (Solé et al., 2000). Países anteriormente emigratorios, van a empezar a transformarse en zonas de inmigración, con el retorno, en un primer tiempo, de antiguos emigrantes y con la llegada de inmigrantes extranjeros, posteriormente. Si en 1975-1980, esta llegada es todavía poco importante en España, Italia o Malta, el impacto es más significativo en el caso de Grecia o de Eslovenia, para los cuales las tasas anuales de migración neta alcanzan $+6,0 \%$ y $+3,9 \%$, respectivamente.

Las diferencias entre el "Norte" y el "Sur" o el "Oriente", empiezan a ampliarse a partir de 1980 (Sánchez Picón y Aznar Sánchez, 2002), incluso si Libia con una tasa anual de migración neta de $+10,6 \%$ en $1980-1985$, y tasas positivas a lo largo del período 1955-2050, representa una situación un tanto atípica en el seno de un "Sur" bastante uniforme y que se caracteriza principalmente por su emigración. Efectivamente, su singularidad como país productor de petróleo, convierte a Libia en un país demandante de mano de obra hacia el cual se dirigen numerosos inmigrantes.

A partir de 1980, las tasas anuales de migración neta de los países del "Norte" empiezan a incrementarse hasta alcanzar sus niveles máximos en 2000-2005. En el curso de estos cinco años España, por ejemplo, muestra un saldo positivo de más de 2,5 millones de entradas netas, lo que equivale a una tasa anual de migración neta de $+12,0 \%$ o. Por el contrario, y en el curso del mismo período, numerosos países del "Sur" o de "Oriente" presentan tasas negativas, tal como Marruecos, por ejemplo, cuya tasa anual es de $-3,7 \%$, lo que representa más de 555000 salidas netas.

El caso de Israel es igualmente interesante en razón de su originalidad. Desde su independencia del Reino Unido, el 14 de mayo de 1948, Israel presenta una inmigración neta, particularmente importante, tanto en el momento mismo de su creación como estado, con una tasa anual de $+39,2 \%$ en 1950-1955, como en 1990-1995, con una tasa más baja de $+19,7 \%$, cuando se produce un importante flujo inmigratorio procedente de la antigua Unión Soviética.

Estos movimientos "Sur"-"Norte" se deben, según Aragall (2005), a las "disparidades económicas, demográficas, políticas y en materia de seguridad entre países emisores y países receptores", además de por su proximidad geográfica. Sin embargo, las profundas disparidades demográficas entre una y otra orilla explican igualmente la existencia de un flujo entre los dos puntos cardinales, incluso si esta interpretación es tan sólo parcial (Arango, 1989). De tal 
modo, la población del "Norte" está bastante envejecida mientras que la del "Sur" no ha acabado todavía su proceso de transición demográfica. Por otro lado, mientras que las necesidades de mano de obra del "Norte" no estaban todavía satisfechas (Aubarell, 2005), la oferta del "Sur" se enfrentaba a un mercado de trabajo incapaz de absorber una demanda de empleo acentuada por una intensa natalidad. Las consecuencias actuales y futuras de la reciente crisis económica mundial, caracterizada por su magnitud y velocidad, podrían modificar este escenario, frenando la intensidad de los flujos migratorios entre uno y otro lado del Mediterráneo con la adopción de medidas de protección de los mercados de trabajo de los países del "Norte" y podrían suponer tensiones económicas pero, sobre todo, sociales en los países de salida. Por otro lado, las migraciones actuales no parecen estar en medida de reducir los efectos del envejecimiento demográfico del conjunto del Mediterráneo si se considera que muchas de ellas se producen en su seno, es decir, que son internas, y que la posible aunque reducida reducción del envejecimiento en los países de acogida se vería contrarestada por su aumento en los países menos envejecidos.

Por último, se han calculado las fechas en las cuales se alcanzarían determinados niveles correspondientes a algunos indicadores del envejecimiento demográfico (tabla 12). Estos indicadores no pretenden proporcionar una medida exacta del envejecimiento sino más bien ilustrar una posible evolución futura de las diversas regiones que componen el Mediterráneo, a la luz de la evolución pasada y de los datos existentes ${ }^{12}$. Así, se han considerado las fechas para las cuales:

- La relación entre $\mathrm{P}_{65+}$ y $\mathrm{P}_{0-19}$ sobrepasa el 50\%: se trata de uno de los primeros pilotos en haberse encendido en los países pioneros en la materia (Francia, Italia y Grecia).

- $\mathrm{P}_{65+}$ sobrepasa $\mathrm{P}_{0-19}$ : se trata de un indicador simbólico.

- $\mathrm{P}_{65+} / \mathrm{P}_{\text {TOT }}$ sobrepasa 20\%: es una medida próxima de la anterior.

- $\mathrm{P}_{80+} / \mathrm{P}_{\mathrm{TOT}}$ sobrepasa 5\%: es un indicador del sobre envejecimiento.

- La relación entre $\mathrm{P}_{65+}$ y $\mathrm{P}_{20-64}$ sobrepasa 30\%: es una medida del peso de los "seniors" que tiene que soportar la población potencialmente activa.

- La relación entre la suma de $\mathrm{P}_{0-19}$ y $\mathrm{P}_{65+}$, por un lado, y $\mathrm{P}_{20-64}$, por otro lado, alcanza su nivel máximo: es una medida del peso de la población potencialmente inactiva con respecto a la población potencialmente activa.

12 Las fechas han sido calculadas por interpolación lineal cuando el valor de un nivel se alcanzaba antes de 2050, y por extrapolación lineal de los valores correspondientes a los años 2045-2050 cuando el nivel no había sido alcanzado antes de esta última fecha. 
TABLA 12

FECHAS A LAS CUALES SE ALCANZARÁN DIVERSOS NIVELES DE ALGUNOS INDICADORES DEL ENVEJECIMIENTO DEMOGRÁFICO EN LA POBLACIÓN MUNDIAL Y EN LOS PAÍSES DEL MEDITERRÁNEO

\begin{tabular}{lcccccc}
\hline & $\begin{array}{c}\mathrm{P}_{65+} / \mathrm{P}_{0-19} \\
\text { sobrepasa el 50\% }\end{array}$ & $\begin{array}{c}\mathrm{P}_{65+} \\
\mathrm{P}_{0-19}\end{array}$ & $\begin{array}{c}\text { sobrepasa } \\
\text { sobrepasa el 20\% }\end{array}$ & $\begin{array}{c}\mathrm{P}_{65+} / \mathrm{P}_{\mathrm{TOT}} \\
\text { sobrepasa el 5\% }\end{array}$ & $\begin{array}{c}\mathrm{P}_{80} / \mathrm{P}_{\mathrm{TOT}} \\
\text { sobrepasa el 30\% }\end{array}$ & $\begin{array}{c}\mathrm{P}_{05-19} / \mathrm{P}_{20-64} \\
\text { Minimo }\end{array}$ \\
\hline Planeta & $2035-2040$ & - & - & - & - & 2025 \\
Mediterráneo & $2025-2030$ & - & $2045-2050$ & $2040-2045$ & $2035-2040$ & 2020 \\
Albania & $2020-2025$ & - & $2045-2050$ & $2035-2040$ & $2030-2035$ & 2020 \\
Argelia & $2040-2045$ & - & - & - & $2045-2050$ & 2040 \\
Bosnia & $2000-2005$ & $2020-2025$ & $2025-2030$ & $2030-2035$ & $2020-2025$ & 2015 \\
Chipre & $2005-2010$ & $2040-2045$ & $2030-2035$ & $2030-2035$ & $2025-2030$ & 2015 \\
Croacia & $1990-1995$ & $2015-2020$ & $2015-2020$ & $2015-2020$ & $2010-2015$ & 2010 \\
Egipto & - & - & - & - & - & 2040 \\
Eslovenia & $1995-2000$ & $2015-2020$ & $2015-2020$ & $2015-2020$ & $2015-2020$ & 2010 \\
España & $1990-1995$ & $2020-2025$ & $2020-2025$ & $2005-2010$ & $2015-2020$ & 2005 \\
Francia & $1985-1990$ & $2025-2030$ & $2015-2020$ & $2005-2010$ & $2010-2015$ & 2010 \\
Grecia & $1985-1990$ & $2010-2015$ & $2015-2020$ & $2010-2015$ & $2010-2015$ & 2010 \\
Israel & $2030-2035$ & - & - & $2035-2040$ & $2035-2040$ & 2035 \\
Italia & $1985-1990$ & $2000-2005$ & $2005-2010$ & $2000-2005$ & $2000-2005$ & 2000 \\
Líbano & $2030-2035$ & - & - & - & $2045-2050$ & 2020 \\
Libia & $2040-2045$ & - & - & - & $2045-2050$ & 2035 \\
Malta & $2000-2005$ & $2015-2020$ & $2015-2020$ & $2020-2025$ & $2015-2020$ & 2010 \\
Marruecos & $2040-2045$ & - & - & - & - & 2040 \\
Serbia & $2000-2005$ & $2040-2045$ & $2035-2040$ & $2035-2040$ & $2025-2030$ & 2015 \\
Siria & $2045-2050$ & - & - & - & - & 2040 \\
T. Palestinos & - & - & - & - & - & 2050 \\
Túnez & $2030-2035$ & - & $2045-2050$ & - & $2040-2045$ & 2015 \\
Turquía & $2035-2040$ & - & - & - & $2045-2050$ & 2025 \\
\hline
\end{tabular}

Fuente: Cálculos de los autores, United Nations, World Population Prospects, the 2008 Revision, www.un.org

De este modo, es posible no sólo visualizar el tempo del envejecimiento alrededor del Mediterráneo, sino también identificar similitudes entre países. El gráfico 4 representa los datos a los que se acaba de aludir y descubre diferencias muy significativas que separan los países en tres grupos más o menos homogéneos:

- Croacia, Eslovenia, España, Francia, Grecia, Italia y Malta.

- Albania, Bosnia, Chipre, Israel, Líbano, Serbia, Túnez y Turquía.

- Argelia, Egipto, Libia, Marruecos, Siria y Territorios Palestinos 
GRÁFICO 4

FECHAS A LAS CUALES SE ALCANZARÁN DIVERSOS NIVELES DE ALGUNOS INDICADORES DEL ENVEJECIMIENTO DEMOGRÁFICO EN LA POBLACIÓN MUNDIAL Y EN LOS PAÍSES DEL MEDITERRÁNEO

Planeta

Mediterráneo

T.Palestinos

Siria

Marruecos

Egipto

Argelia

Libia

Israel

Turquía

Líbano

Albania

Túnez

Serbia

Chipre

Bosnia

Malta

Eslovenia

Croacia

Grecia

Francia

España

Italia

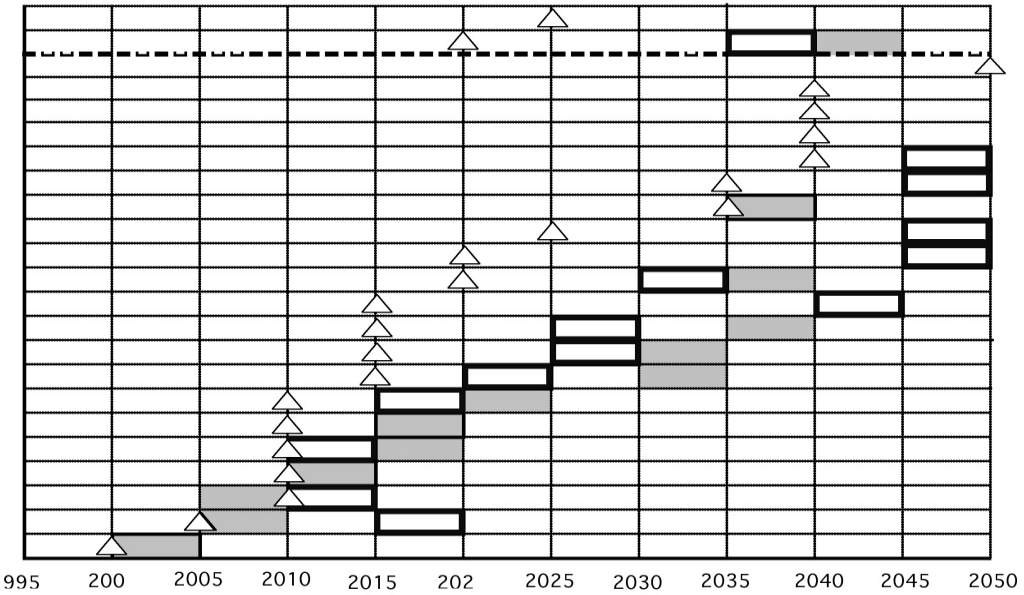

P80+/PTOT sobrepasa el 5\%

P65+ /P20-64 sobrepasa el 30\%

(P0-19+P65+)/P20-64 Mínimo

Fuente: United Nations, World Population Prospects, the 2008 Revision, www.un.org

Estudios Geográficos, Vol. LXX, 267, pp. 661-705, julio-diciembre 2009 ISSN: 0014-1496, eISSN: 1988-8546, doi: 10.3989/estgeogr.0469 
Si el primer grupo contiene la mayor parte de los países del "Norte", el segundo mezcla "Norte" y "Oriente" y el último grupo reúne a países del "Sur" y de "Oriente", los tempos ponen al descubierto que únicamente determinados niveles ya han sido alcanzados, otros siéndolo eventualmente en un futuro más o menos lejano. Efectivamente, algunos de estos indicadores reflejan una situación actual, aunque no generalizable a la totalidad de las poblaciones estudiadas $\left(\mathrm{P}_{65+} / \mathrm{P}_{0-19}>50 \%\right.$ y $\left.\mathrm{P}_{80+} / \mathrm{P}_{\mathrm{TOT}}>5 \%\right)$, mientras que otras son de naturaleza prospectiva, total o parcialmente. Esto supone, entre otras cosas, que en la medida en que las hipótesis de Naciones Unidas no lograran materializarse, algunas tendencias seguirían prolongándose en el tiempo, tanto en un sentido como en otro. Así, por ejemplo, si la fecundidad no disminuye en el "Sur" o el "Oriente", tal y como lo prevén las hipótesis de Naciones Unidas, su envejecimiento demográfico debería ser menos intenso pero, simultáneamente, su población potencialmente activa (20-64 años) debería incrementarse en más de los 117 millones de personas previstas en el curso del período 2000-2050. Esto supondría una presión sobre el mercado laboral del "Sur" y de "Oriente" mucho más intensa que en la actualidad, si se tiene en cuenta que su población potencialmente activa sólo se incrementó, si se puede expresar así, en 87 millones de individuos en el curso del período anterior 1950-2000. Por otro lado, si la recuperación de la fecundidad no se produce en el "Norte" en las proporciones propuestas por Naciones Unidas, todo deja entrever que no sólo su envejecimiento será más intenso sino que, además, su población potencialmente activa disminuirá con toda probabilidad todavía más que los 11 millones previstos, lo cual deja entrever una potente llamada de mano de obra, no sólo con escasa cualificación, sino también de cualificación más alta, con el fin de poder hacer frente a la ausencia de renovación de puestos de trabajo que requieren estos altos niveles de cualificación.

El futuro del Mediterráneo esta pues sometido a fuertes incertidumbres tanto en cuanto a la evolución futura de su fecundidad se refiere, como a la del envejecimiento de su estructura por edad, el hecho de no mencionar las demás dimensiones demográficas no significando por ello una mayor capacidad de previsión de éstas. Este futuro estará también determinado por la reducción de las diferencias económicas (ver tabla 13), algo que de momento parece está pasando, con una disminución de las diferencias entre los PIB/habitante extremos, que pasan de cerca de 15 en 1985 a aproximadamente 8 en 2005. 
TABLA 13

INDICADORES ECONÓMICOS DE ALGUNOS PAÍSES DEL MEDITERRÁNEO EN 1985 Y 2005 (EN DÓLAR US)

\begin{tabular}{|c|c|c|}
\hline $\begin{array}{l}\text { Indicadores } \\
\text { económicos }\end{array}$ & $\begin{array}{c}\text { PIB/hab } \\
1985\end{array}$ & $\begin{array}{c}\text { PIB/hab } \\
2005\end{array}$ \\
\hline Planeta & 2.760 & 9.470 \\
\hline Albania & - & 5.420 \\
\hline Argelia & 2.400 & 6.770 \\
\hline Bosnia & - & 7.790 \\
\hline Chipre & 3.720 & 22.230 \\
\hline Croacia & 一 & 12.750 \\
\hline Egipto & 700 & 4.440 \\
\hline España & 4.800 & 25.820 \\
\hline Francia & 10.390 & 30.540 \\
\hline Grecia & 3.970 & 23.620 \\
\hline Israel & 5.360 & 25.280 \\
\hline Italia & 6.350 & 28.840 \\
\hline Líbano & - & 5.740 \\
\hline Libia & 7.500 & - \\
\hline Malta & 3.710 & 18.960 \\
\hline Marruecos & 750 & 4.360 \\
\hline Serbia & - & - \\
\hline Eslovenia & - & 22.160 \\
\hline Siria & 1.680 & 3.740 \\
\hline T. Palestinos & - & - \\
\hline Túnez & 1.290 & 7.900 \\
\hline Turquía & 1.230 & 8.420 \\
\hline
\end{tabular}

Fuente: Lévy 1985 et World Bank 2006.

LOS DESAFÍOS DEL MEDITERRÁNEO EN FORMA DE CONCLUSIÓN

2005 fue declarado "Año del Mediterráneo". Quizás sea deseable que al varias veces milenario Mediterráneo se le conceda un poco más de un año, aunque sólo fuese en razón de su gran edad. Independientemente de este hecho, en sus conclusiones, la Declaración de Barcelona del año 1995 sugería que era por medio de los intercambios de jóvenes que deberían prepararse las generaciones futuras a una colaboración más estrecha entre los socios euro mediterráneos. Quizás debería reconocerse a las personas mayores, los "seniors", al 
margen o más allá de esta Declaración, un protagonismo más importante en un futuro próximo, teniendo en cuenta el progresivo e imparable incremento de su importancia, no sólo numérica, sino también económica, política y social. La mirada tanto de los investigadores como de los responsables políticos, no sólo debería buscar a discernir orillas lejanas de contornos inciertos, sino que además y sobre todo debería reconocer un futuro extremadamente claro que sigue caminos ya recorridos por el "Norte". Se trata entonces de tender una mano, con sus herramientas, sus errores y sus experiencias.

Los países del "Sur" y de "Oriente" deberían poder beneficiarse de numerosas ventajas con respecto a los del "Norte". En primer lugar, la lección sacada de estos últimos debería ser bien aprendida por los primeros tan numerosos han sido los análisis, estudios, investigaciones, artículos, escritos, recomendaciones, tesis, reuniones, coloquios, debates, etc., que les han sido dedicados, pero, ¿lo será realmente? En segundo lugar, el fenómeno tiene la virtud de anunciarse con suficiente antelación y no de surgir de la nada o de presentarse sin avisar ( $\mathrm{Pa}$ rant, 1997 y 2000; Zamora López, 2005). No sería perdonable fingir sorpresa, incluso si hay lugar para inquietarse por no haber sabido medir completamente su profundidad ni sus diversas consecuencias, más allá de las estrictamente económicas a las cuales, demasiado a menudo, se limitan las advertencias. Se está en derecho de preguntarse si iesto ha sido así porque no hay otras consecuencias o bien porque éstas presentan menos interés que las anteriores?

El envejecimiento demográfico de la cuenca mediterránea no ofrece ninguna duda a pesar de las diferencias de niveles y de ritmos observados. Sin embargo, la idea de un "Norte" envejecido frente a unos "Sur" y "Oriente" jóvenes, no es completamente exacta. Algunos países están situados en una posición intermedia, mientras que otros verán, con toda probabilidad, incrementarse su envejecimiento a un ritmo muy reducido, eso sí, en ausencia de cambios imprevisibles.

Existen, no obstante, otros riesgos o fenómenos que deben igualmente ser considerados. De tal modo y como ya ha sido resaltado, es más que probable que los diferenciales de crecimiento de poblaciones potencialmente activas de un lado y otro del Mediterráneo, deberían protagonizar un papel determinante en la intensificación de futuros flujos "Sur"-"Norte". No sólo, como ha sido recordado, existen diferencias demográficas importantes, sino que igualmente se mantienen distancias importantes en cuanto a desarrollo económico se refiere, y quizás sea esto más importante que lo anterior para poder dibujar un futuro menos borroso.

Recibido: 29/06/2009

Aceptado: 30/09/2009 


\section{BiBLIOGRAFÍA}

Arango, J. (1989): Disparidades demográficas y potencial migratorio en el Mediterráneo, in M.A. Roque (ed.), Movimientos Humanos en el Mediterráneo Occidental, Barcelona: Institut Català d'Estudis Mediterranis, pp. 117-135.

Arango, J. (2003): Inmigración y diversidad humana. Una nueva era en las migraciones internacionales. Revista de Occidente, $n^{\circ} 268$, pp. 5-20.

Aragall, X. (2005): Migraciones internacionales: el espacio euromediterráneo en la agenda global. Instituto Europeo del Mediterráneo y Fundación CIDOB, pp. 218-221.

Aubarell, G. (2005): Inmigración en el espacio euromediterráneo. Documentos. Proceso euromediterráneo e inmigración, www.iemed.org.

Bachrach, C. (2001): Comment: the puzzling persistence of postmodern fertility preferences. Population and Development Review, supplement to $\mathrm{n}^{\mathrm{o}} 27$, pp. 332-338.

Becker, G. (1987): Tratado sobre la familia. Alianza Editorial. Madrid.

Bongaarts, J. (2001): Fertility and reproductive preferences in post-transitional societies. Population and Development Review, supplement to $\mathrm{n}^{\circ} 27$, pp. 260-281.

Caldwell, J. C. (1978): "A theory of fertility: from high plateau to destabilization". Population and Development Review, vol. 4, $\mathrm{n}^{\circ} 3$.

Coale (1973): "The demographic transition", en Proceedings of the IUSSP Conference. Ordina Editions. Liège.

Chesnais, J. C. (1999): "La fécondité au xxº siècle: une baisse irrégulière, mais profonde et irrésistible", en Bardet, J.-P. et Dupâquier, J. (eds.). Histoire des populations de l'Europe. III. Les temps incertains. 1914-1998. Fayard. Paris.

Davis, K. (1963): "The theory of change and response in modern demographic history". Population Index, vol. 29, n ${ }^{\circ} 4$.

Davis, K., Bernstam, M. S. and Ricardo-Campbell, R. (eds.) (1986): "Below-replacement fertility in industrial societies". Population and Development Review, a supplement to vol. 12.

Delgado, M. (2003): "La fecundidad en España a fines del siglo xx." Sistema, 175-176: 51-66.

EUROSTAT (2008): "Ageing characterises the demographic perspectives of the European societies". Population and Social Conditions. Statistics in focus. 72/2008. Eurostat.

Faour, M. (1989): Fertility Policy and Family Planning in the Arab Countries. Studies in Family Planning, vol. 20, $\mathrm{n}^{\circ}$ 5, pp. 254-263.

Fargues, P. (1986): Un siècle de transition en Afrique méditerranéenne: 1885-1985. Population, 4le Année, no 2, pp. 205-232.

Fargues, P. (1988): La baisse de la fécondité arabe Population (French Edition), 43e Année, $n^{\circ}$ 6, pp. 975-1004.

Faron, O. et George, P. (1999): Les migrations européennes de la Grande Guerre à nos jours, in Bardet, J.-P. et Dupaquier, J. (eds.). Histoire des populations de l'Europe. III. Les temps incertains. 1914-1998. Fayard. Paris. 
Frenk, J., Bobadilla, J. L., Stern, C., Frejka, et Lozano. (1991): Elements for a theory of the health transition. Health Transition Review, vol. 1, no 1, pp. 21-37.

Frejka, T. and Sardon, J.-P. (2004): Childbearing Trends and Prospects in Low-Fertility Countries. A Cohort Analysis. Dordrecht: Kluwer Academic Publishers.

Höhn, C., and Mackensen, R. (eds.) (1981): Determinants of fertility Trends: Theories Re-examined. Ordina Editions. Liège.

Keilman, N. (1998): How accurate are the United Nations World Population projections? Population and Development Review, vol. 24, Issue Supplement, pp. 15-41.

Keyfitz, N. (1986): "The family that does not reproduce itself", en Davis, K., Bernstam, M. S. and Ricardo-Campbell, R. (eds.). "Below-replacement fertility in industrial societies". Population and Development Review, a supplement to vol. 12.

Kohler, H.-P., Billari, F. C, and Ortega, J. A. (2002): The Emergence of Lowest-Low Fertility in Europe During the 1990s. Population and Development Review, 28, 4: 641-680.

Kupiszewski, M., Bijak, J. and Nowok, B. (2005): Impact of future demographic trends in Europe. Conseil de l'Europe, DG3/CAHP10 (2005) 6 final.

Leasure, W. J. (1982): "La baisse de la fécondité aux Etats-Unis de 1800 à 1860". Population, $\mathrm{n}^{\mathrm{o}}$ 3. Paris.

Leibenstein, H. (1981): "Economic decision theory and human fertility behavior: A speculative essay". Population and Development Review, vol. 7, $\mathrm{n}^{\circ} 3$.

Lesthaeghe, R. (1980): "On the social control of human reproduction". Population and Development Review, vol. 6, n ${ }^{\circ} 4$.

Lesthaeghe, R. (1983): "A century of demographic and cultural change in western Europe: An exploration of underlying dimensions". Population and Development Review, vol. 9, $\mathrm{n}^{\circ} 3$.

Lesthaeghe, R. et Wilson, C. (1982): "Les modes de production, la laïcisation et le rythme de la baisse de la fécondité en Europe de l'Ouest de 1870 à 1930". Population, $\mathrm{n}^{\mathrm{o}}$ 3. Paris.

Lesthaeghe, R. and Willems, P. (1999): Is low fertility a temporary phenomenon in the European Union? Population and Development Review, 25, 2, 221-228.

Lévy, M. L. (1985): Tous les pays du monde (1985). Population et Sociétés, no 193, juillet-août, Paris.

Livi Bacci, M. (1988): Ensayo sobre la historia demográfica europea. Población y alimentación en Europa. Ariel. Barcelona.

Mackenbach, J. P. (1996): The contribution of medical care to mortality decline: McKeown revisited. Journal of Clinical Epidemiology, vol. 49, pp. 1207-1213.

McKeown, T. (1976): The modern rise of population. Arnold. Londonn.

Meslé, F. et Vallin, J. (1997): La mortalité dans le monde: tendances et perspectives, in Chasteland, J.-C. et Chesnais, J.-C. (eds.). La population du monde. Enjeux et problèmes. Travaux et Documents, $\mathrm{n}^{\circ}$ 139. INED. PUF. Paris.

Obermeyer, C. M. (1992): Islam, Women, and Politics: The Demography of Arab Countries. Population and Development Review, vol. 18, nº 1, pp. 33-60. 
Omran, A. R. (1971): The epidemiologic transition. A theory of the epidemiology of population change. Milbank Memorial Fund Quarterly, vol. 49, nº 4.

Parant, A. (1997): Le vieillissement démographique de la Communauté européenne. Population et Sociétés, n 321, février 1997.

Parant, A. (2000): Le vieillissement démographique. Anti-hasard et défaut de prospective. Espace-Populations-Sociétés, n² 2000-3, pp. 339-361.

Rogers, R.G. and Hackenber, G. R. (1987): Extending epidemiologic transition theory. Social Biology, 3-4, otoño-invierno, pp. 234-243.

Sánchez Picón, A. y Aznar Sánchez, J. A. (2002): Diversidad migratoria en las dos orillas del Mediterráneo. De las experiencias históricas al desafío actual. Mediterráneo Económico: Procesos migratorios, economía y personas, $\mathrm{n}^{\circ} 1$.

Solé, C., Parella, S., Alarcón, A., Bergalli, V. y Gilbert, F. (2000): El impacto de la inmigración en la sociedad receptora. Revista Española de Investigaciones Sociológicas, 90, pp. 131-157.

United Nations (2005): World Mortality Report 2005. ST/ESA/SER/A/252, New York.

United Nations (2006): World Population Policies 2005. ST/ESA/SER.A/254, New York.

United Nations (2009): World Population Prospects. The 2008 Revision. ESA/P/WP.193, New York. http://esa.un.org/unpp/index.asp?panel=2

Van de Kaa, D. J. (2001): Postmodern fertility preferences: from changing value orientation to the new behavior. Population and Development Review, supplement to $n^{\circ} 27$, pp. 290-331.

World Bank (2006): World development report 2007: development and the next generation. World Bank, Washington.

Zamora López, F. (2005): La España que viene. Papeles de Economía Española, FUNCAS (Fundación de Cajas de Ahorro), Madrid, nº 104.

\section{RESUMEN}

Entre 1950 y 2050, la población de 65 o más años del Mediterráneo pasará de 15 a 126 millones de personas, es decir, que en 2050 uno de cada cinco habitantes del Mediterráneo será un "senior". El proceso de envejecimiento demográfico en el espacio mediterráneo muestra, en miniatura, las transformaciones de la estructura demográfica que afectará al conjunto del planeta. Todos los países del Mediterráneo, independientemente de sus diferencias demográficas, económicas, sociales, políticas, culturales, etc., se verán sometidos a cambios notables de su estructura por edad, que se caracterizarán por un incremento tanto absoluto como relativo de los "seniors". En este contexto, si bien se apreciarán diferencias importantes, tanto en el ritmo como en la intensidad del fenómeno, lo verdaderamente relevante será la universalidad de éste.

Palabras ClaVE: envejecimiento demográfico; dinámica demográfica; proyecciones; Mediterráneo. 


\begin{abstract}
Between 1950 and 2050, population aged 65 and over in the Mediterranean will pass from 15 to 126 million people; that is to say, one in five inhabitants of the Mediterranean area will be a senior in 2050. The process of population aging in the Mediterranean region shows, on a small scale, the changing demographic structure that will affect the entire planet. All Mediterranean countries, regardless of their demographic, economic, social, political and cultural differences, will be subject to significant changes in its age structure, which will become characterized by an increase in both the absolute and relative amount of the seniors. In this context, although differences will be significant among countries in both the pace and the intensity of the phenomenon, the universality of it emerges as the relevant feature.
\end{abstract}

KEY WORDS: aging population; demographic dynamics; projections; Mediterranean.

\title{
RÉSUMÉ
}

Entre 1950 et 2050, la population de 65 ans ou plus de la Méditerranée passera de 15 à 126 millions de personnes, c'est-à-dire, qu'en 2050 un habitant sur cinq de la Méditerranée sera un "senior". Le processus de vieillissement démographique dans l'espace méditerranéen montre, en miniature, les transformations de la structure démographique qui touchera l'ensemble de la planète. Tous les pays de la Méditerranée, indépendamment de leurs différences démographiques, économiques, sociales, politiques, culturelles, etc., seront soumis à des changements notables de leur structure par âges, qui se caractériseront par un accroissement tant absolu comme relatif des "seniors". Dans ce contexte, même si des différences importantes peuvent s'apprécier, tant en ce qui concerne le rythme comme l'intensité du phénomène, l'universalité de celui-ci est réellement le fait remarquable.

Mots CLÉs: vieillissement démographique; dynamique démographique; projections; Méditerranée. 


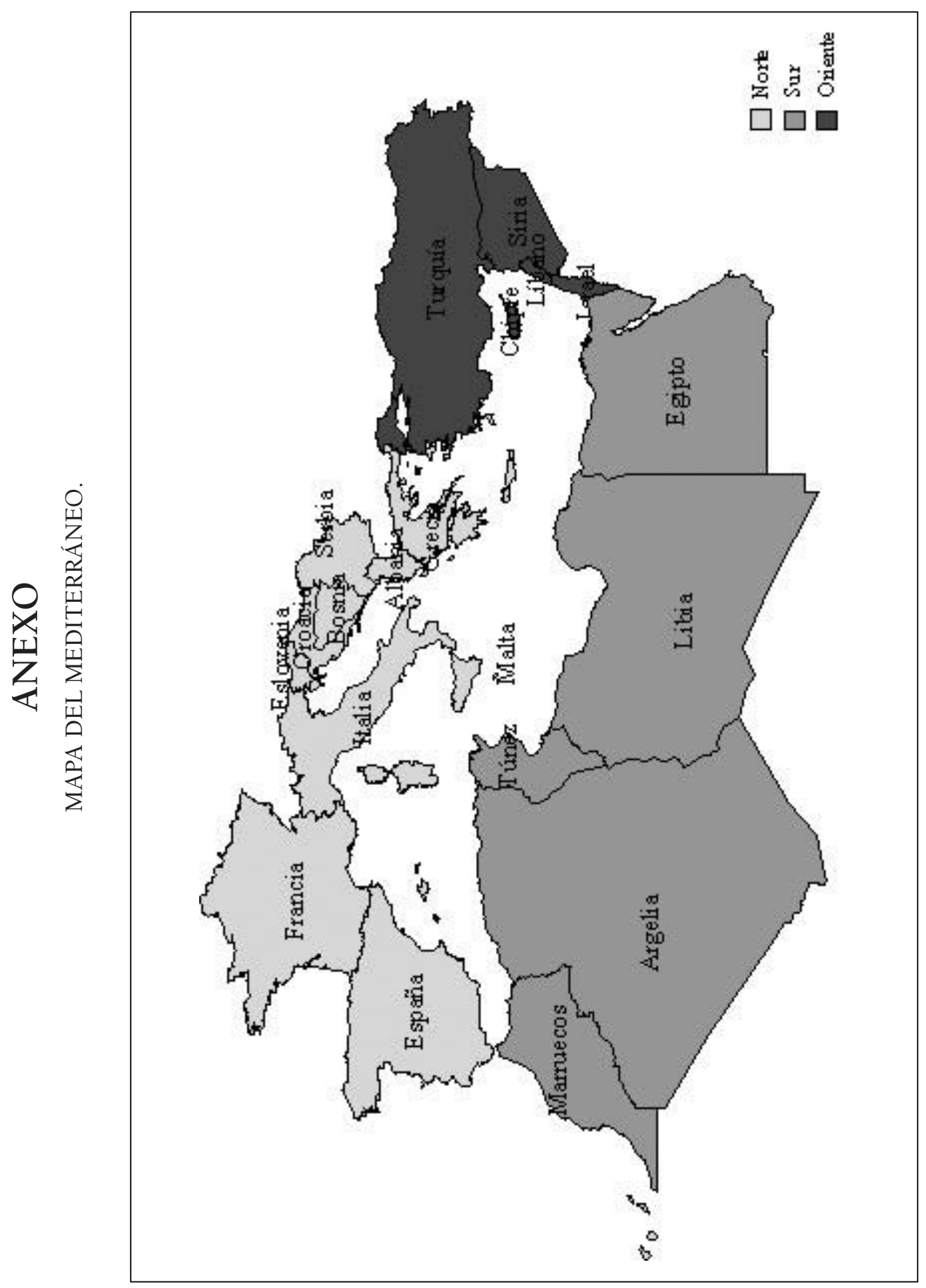

Estudios Geográficos, Vol. LXX, 267, pp. 661-705, julio-diciembre 2009 ISSN: 0014-1496, eISSN: 1988-8546, doi: 10.3989/estgeogr.0469 